\title{
Preclinical screening of histone deacetylase inhibitors combined with ABT-737, rhTRAIL/MD5-1 or 5-azacytidine using syngeneic VkMYC multiple myeloma
}

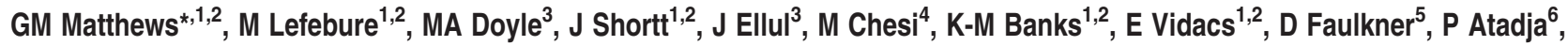 \\ PL Bergsagel ${ }^{4}$ and RW Johnstone ${ }^{1,2}$
}

Multiple myeloma (MM) is an incurable malignancy with an unmet need for innovative treatment options. Histone deacetylase inhibitors (HDACi) are a new class of anticancer agent that have demonstrated activity in hematological malignancies. Here, we investigated the efficacy and safety of $\mathrm{HDACi}$ (vorinostat, panobinostat, romidepsin) and novel combination therapies using in vitro human MM cell lines and in vivo preclinical screening utilizing syngeneic transplanted $\mathrm{Vk}^{\star} \mathrm{MYC} M \mathrm{MM}$. HDACi were combined with ABT-737, which targets the intrinsic apoptosis pathway, recombinant human tumour necrosis factor-related apoptosis-inducing ligand (rhTRAIL/MD5-1), that activates the extrinsic apoptosis pathway or the DNA methyl transferase inhibitor 5-azacytidine. We demonstrate that in vitro cell line-based studies provide some insight into drug activity and combination therapies that synergistically kill MM cells; however, they do not always predict in vivo preclinical efficacy or toxicity. Importantly, utilizing transplanted Vk*MYC MM, we report that panobinostat and 5-azacytidine synergize to prolong the survival of tumor-bearing mice. In contrast, combined HDACi/rhTRAIL-based strategies, while efficacious, demonstrated on-target dose-limiting toxicities that precluded prolonged treatment. Taken together, our studies provide evidence that the transplanted Vk*MYC model of MM is a useful screening tool for anti-MM drugs and should aid in the prioritization of novel drug testing in the clinic.

Cell Death and Disease (2013) 4, e798; doi:10.1038/cddis.2013.306; published online 12 September 2013

Subject Category: Cancer

Multiple myeloma (MM) is an incurable malignancy of plasma cells $^{1,2}$ characterized by clonal dysproteinemia, immune deregulation and end-organ toxicities associated with lytic bone destruction, renal failure, anemia and hypercalcemia. ${ }^{3,4}$ Advances in the treatment of MM have been made recently; ${ }^{5}$ however, many patients fail to respond or relapse after initial response, highlighting the requirement for novel agents and combination regimens. ${ }^{6,7}$ Histone deacetylase inhibitors (HDACi) have demonstrated activity in hematological malignancies, ${ }^{8-10}$ although resistance and dose-limiting toxicities are restricting their use. ${ }^{11,12}$ Here, we evaluated the potential of augmenting antitumor activities of HDACi by their combination with agents targeting multiple apoptotic pathways or DNA methyltransferases. Preclinical evaluation of efficacy and associated toxicities of this approach were evaluated using the $\mathrm{Vk}^{\star} \mathrm{MYC}$ model of MM.
Vorinostat (suborylanilide hydroxamic acid (SAHA)), an HDACi targeting multiple HDACs and romidepsin (depsipeptide), a class I-selective HDACi, are FDA approved for the treatment of cutaneous T-cell lymphoma. ${ }^{13,14}$ Panobinostat (LBH-589), a cinnamic hydroxamic acid targeting multiple HDACs, ${ }^{15}$ is undergoing phase III trials in combination with agents including bortezomib and dexamethasone in relapsed and refractory MM. HDACi induce apoptosis mainly via the intrinsic pathway ${ }^{9}$ through events including altered cell cycle progression and/or cellular differentiation.,13,15-17 Hyperacetylation of non-histone proteins, including p53 and Hsp-90, may also have important roles in mediating antitumor effects of HDACi. ${ }^{18}$ We posit that combining HDACi with agents targeting the intrinsic or extrinsic (death receptor) apoptotic pathways, or DNA-methyltransferases, could enhance therapeutic effects of $\mathrm{HDACi}^{17}$ while reducing toxicities.

\footnotetext{
${ }^{1}$ Gene Regulation Laboratory, Cancer Therapeutics, Peter MacCallum Cancer Centre, St Andrews Place, East Melbourne, Victoria, Australia; ${ }^{2}$ Sir Peter MacCallum Department of Oncology, University of Melbourne, East Melbourne, VIC, Australia; ${ }^{3}$ Bioinformatics Core Facility, Peter MacCallum Cancer Centre, St Andrews Place, East Melbourne, VIC, Australia; ${ }^{4}$ Comprehensive Cancer Centre and Laboratory Medicine and Pathology, Mayo Clinic Arizona, Scottsdale, AZ, USA; ${ }^{5}$ Department of Pathology, Peter MacCallum Cancer Centre, St Andrews Place, East Melbourne, VIC, 3002, Australia and ${ }^{6}$ Novartis Institutes for Biomedical Research, Cambridge, MA, USA

${ }^{*}$ Corresponding author: GM Matthews, Gene Regulation Laboratory, Cancer Therapeutics, Peter MacCallum Cancer Centre, St Andrews Place, East Melbourne, VIC 3002, Australia. Tel: +61 39656 3724; Fax: +61 39656 1411; E-mail: geoff.matthews@ petermac.org

Keywords: multiple myeloma; histone deacetylase inhibitors; intrinsic apoptosis; extrinsic apoptosis; DNA methylation

Abbreviations: 5-AZA, 5-azacytidine; ANOVA, analysis of variance; BH3, Bcl-2 homology domain 3; CAMERA, correlation adjusted mean rank; c-FLIP, cytosolic Flicelike inhibitory protein; Cl, combination index; DNMTi, DNA methyl transferase inhibitor; DR-4/5, death receptor-4/5; FDR, false discovery rate; HDAC, histone deacetylase; HDACi, histone deacetylase inhibitor; IP, intraperitoneal; JAK, Janus kinase; MGUS, monoclonal gammopathy of underdetermined significance; MM, multiple myeloma; rhTRAIL, recombinant human TNF-related apoptosis-inducing ligand; SAHA, suborylanilide hydroxamic acid; SPEP, serum protein electrophoresis; TNF, tumor necrosis factor; TRAIL, TNF-related apoptosis-inducing ligand

Received 18.12.12; revised 13.6.13; accepted 15.7.13; Edited by Y Shi
} 
The intrinsic apoptotic pathway is regulated by prosurvival (e.g. Bcl-2, Bcl- $\mathrm{X}_{\mathrm{L}}$ ) and proapoptotic (e.g. Bax, Bak) multidomain $\mathrm{Bcl}-2$ proteins, and $\mathrm{Bcl}-2$ homology domain 3 (BH3)-only members. ${ }^{19,20}$ ABT-737, a BH3-only mimetic that binds $\mathrm{Bcl}-2, \mathrm{Bcl}-\mathrm{X}_{\mathrm{L}}$ and $\mathrm{Bcl}-\mathrm{W}$, acts by increasing the amount of free $\mathrm{BH} 3-$ only proteins. ${ }^{21-26}$ The death receptor pathway is stimulated by ligands from the tumor necrosis factor (TNF) family, including TNF-related apoptosis-inducing ligand (TRAIL), binding to death receptors DR-4 (TRAIL-R1) or DR-5 (TRAIL-R2)) on human cells, or DR-5 on murine cells. $^{27,28}$ Indeed, we have demonstrated that combining vorinostat with an agonistic anti-TRAIL receptor (TRAILR) antibody is more effective than single-agent treatment of breast cancer cell lines, ${ }^{29,30}$ whereas ABT-737 resensitizes $\mathrm{Bcl}-2$ - and $\mathrm{Bcl}-\mathrm{X}_{\mathrm{L}}$-overexpressing lymphoma cells to vorinostat. $^{31,32}$

Recent work has demonstrated the potential for DNA methyltransferase inhibitors (DNMTi) in MM. ${ }^{6,33}$ DNMTi reportedly induce apoptosis in $\mathrm{MM}$ cells through the downregulation of Janus kinase-signal transducer and activator of transcription (JAK-STAT) signaling and nuclear factor- $\kappa \mathrm{B}^{6}$ and/or re-expression of epigenetically silenced genes, including tumor suppressors. ${ }^{34}$ Promising preclinical data suggests that HDACi and DNMTi may synergize to induce apoptosis and tumor regression in MM.

The Vk*MYC transgenic mouse ${ }^{3,35}$ represents the pathogenesis and clinical manifestations of human MM. It relies on the activation of MYC in plasma cells leading to histopathological and immunophenotypic features of human $\mathrm{MM}$, including progression from monoclonal gammopathy of undetermined significance (MGUS) to end-organ destructive plasma cell expansion. ${ }^{35}$ Chng et al. ${ }^{36}$ demonstrated MYC activation for the progression of human MGUS to MM, highlighting biological relevance of the $\mathrm{Vk}^{*} \mathrm{MYC}$ model. Moreover, Chesi et al. ${ }^{3,35}$ rigorously validated the ability of this model to predict single-agent drug activity in MM with a positive predictive value for clinical activity of $67 \%$ and a negative predictive value for clinical inactivity of $86 \%$. $\mathrm{Vk}^{*} \mathrm{MYC}$ tumor cells are transplantable into syngeneic mice allowing for therapeutic experiments in large cohorts. ${ }^{35}$

Here, we investigated the potential of combining HDACi with ABT-737, recombinant human TNF-related apoptosisinducing ligand (rhTRAIL)/MD5-1 or 5-azacytidine (5-AZA) in MM. We compared the effects of combination regimens in vitro in human $\mathrm{MM}$ cell lines with efficacy in vivo utilizing Vk*MYC MM. We demonstrate divergent effects of combination therapies in vivo compared with in vitro and identify toxicity profiles that only manifest in syngeneic model systems. We propose testing of new agents using $\mathrm{Vk}^{\star} \mathrm{MYC}$ $\mathrm{MM}$ to aid in more rapid development of active and safe drug combinations for the treatment of MM.

\section{Results}

Differential sensitivities of human MM cell lines to HDACi. Human MM cell lines demonstrated differential time- and dose-dependent sensitivities to HDACi (Figure 1a). OPM-2 cells appeared most sensitive to vorinostat $\left(\mathrm{EC}_{50}=727 \mathrm{nM} ; 48 \mathrm{~h}\right)$ compared with EC50s of 1828, 1896 and $2500 \mathrm{nM}$ for JJN3, RPMI-8226 and U266 cells, respectively. JJN3 cells were the most sensitive line to panobinostat $\left(E_{50}=9 \mathrm{nM} ; 48 \mathrm{~h}\right)$ compared with EC50s of 10, 35 and $16 \mathrm{nM}$ for OPM-2, RPMI-8226 and U266 cells, respectively. JJN3 cells were most sensitive to romidepsin $\left(\mathrm{EC}_{50}<1 \mathrm{nM} ; 48 \mathrm{~h}\right)$ compared with EC50s of $1,1.8$ and $10 \mathrm{nM}$ for U266, RPMI-8226 and OPM-2 cells, respectively. To demonstrate the correlation between HDACi-mediated target inhibition and induction of apoptosis, pharmacodynamic analyses were performed using panobinostat as a reference HDACi using detection of histone-H3 acetylation as the readout. Figure $1 \mathrm{~b}$ shows the dose-dependent acetylation of histone-H3 in each human cell line with panobinostat (0-50 nM; $24 \mathrm{~h})$.

MM cell apoptosis is enhanced by combining HDACi with ABT-737. We have previously demonstrated that overexpression of prosurvival $\mathrm{Bcl}-2$ proteins can inhibit HDACi-induced apoptosis. ${ }^{31,32,37-39}$ We therefore determined whether relative sensitivities of MM cell lines to panobinostat were associated with the expression of Bcl-2 family members. Western blot analysis detected significant Bcl-2 expression in JJN3, OPM-2 and RPMI-8226, with barely detectable levels in U266 (Figure 2a). Bcl- $X_{L}$ was detected in RPMI-8226 and U266, with little detected in JJN3 and OPM-2 cells. Mcl-1 was detected at high levels in all lines tested (Figure 2a), whereas Bcl-w and Bcl-A1 were undetectable (positive controls showed antibody specificity, data not shown). Assessment of microarray expression data sets (Oncomine) suggested that all cell lines expressed $\mathrm{Bcl}-2, \mathrm{Mcl}-1$ and low levels of Bcl-w, whereas the expression of $\mathrm{Bcl}-\mathrm{X}_{\mathrm{L}}$ and $\mathrm{A} 1$ correlated with protein levels by western blot (Supplementary Figure 1). Collectively, these data failed to demonstrate any direct correlation between HDACi sensitivity and expression of prosurvival Bcl-2 family proteins. Given that all four MM cell lines expressed high levels of $\mathrm{Bcl}-2$ and/or $\mathrm{Bcl}-\mathrm{X}_{\mathrm{L}}$, we assessed their sensitivity to ABT$737 .^{23,24}$ All four cell lines were sensitive to $A B T-737$, with the U266 line being slightly more resistant (Figure $2 b$ ).

Combining HDACi with ABT-737 kills B-cell lymphomas more potently than either agent alone, ${ }^{31}$ and we therefore wished to determine the effect of this combination treatment against MM cells. The level of apoptosis following treatment of human MM cells with panobinostat and ABT-737 was significantly greater than single-agent treatment with a combination index $(\mathrm{Cl})<0.9$ demonstrating synergistic cell killing (Figure 2c and Supplementary Figures 2A-D). These studies indicate that combining HDACi with ABT-737 may be a potent method of killing MM cells.

Sensitivity of MM cells to the combination of HDACi and rhTRAIL. Previous studies have demonstrated that HDACi activate the extrinsic apoptosis pathway through the upregulation of death receptors (DR4 and DR5) and their cognate ligands (e.g. TRAIL). ${ }^{29,30}$ We have shown that combining HDACi with agonistic anti-TRAIL receptor antibodies is effective in preclinical models of breast, colon and renal carcinoma. ${ }^{17,30}$ In vitro sensitivity of cells to rhTRAIL correlated with surface TRAIL receptor expression (Figures $3 a$ and b), with RPMI-8226 cells showing the highest expression of DR4 and DR5 and lowest apoptotic threshold 


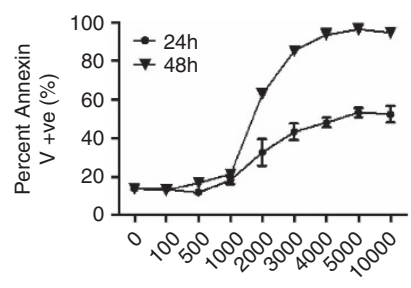

[Vorinostat] $\mathrm{nM}$

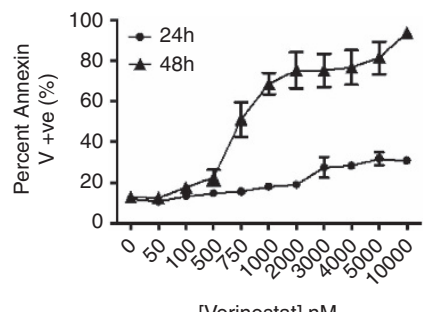

[Vorinostat] nM

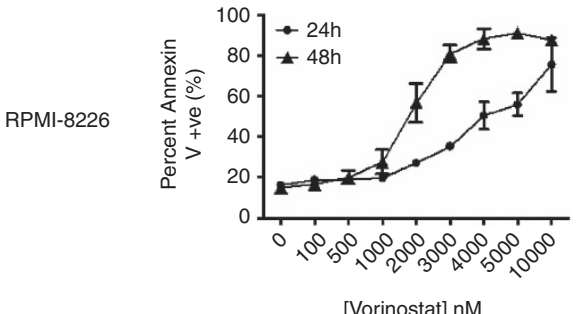

[Vorinostat] $\mathrm{nM}$

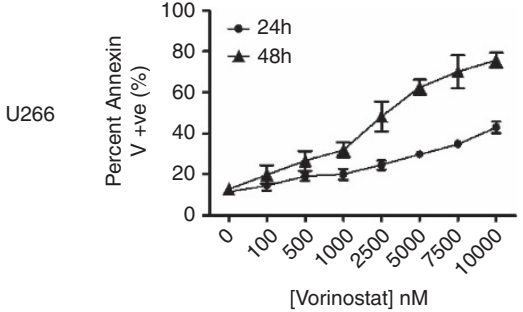

Panobinostat
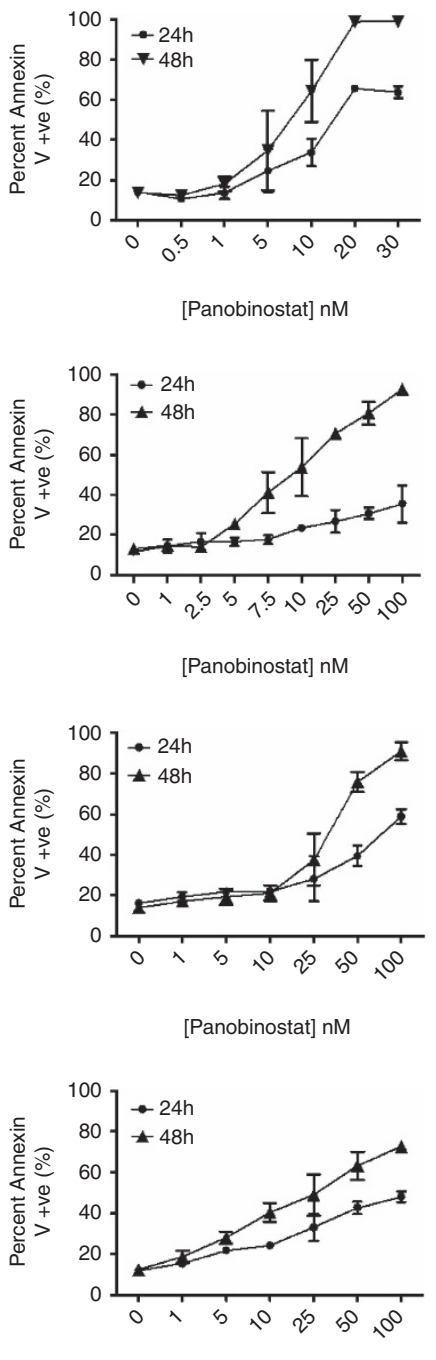

[Panobinostat] nM
Romidepsin
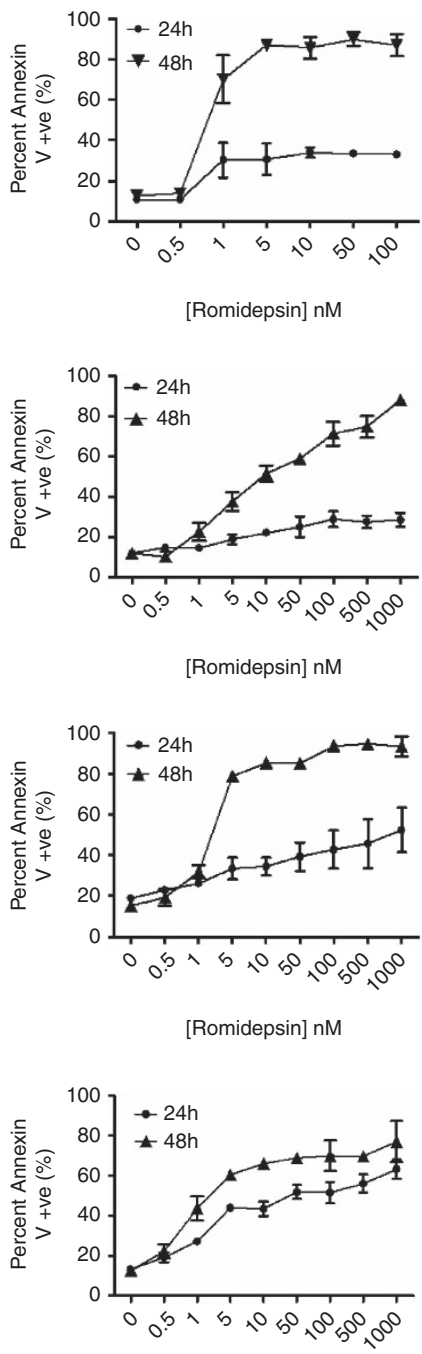

[Romidepsin] nM

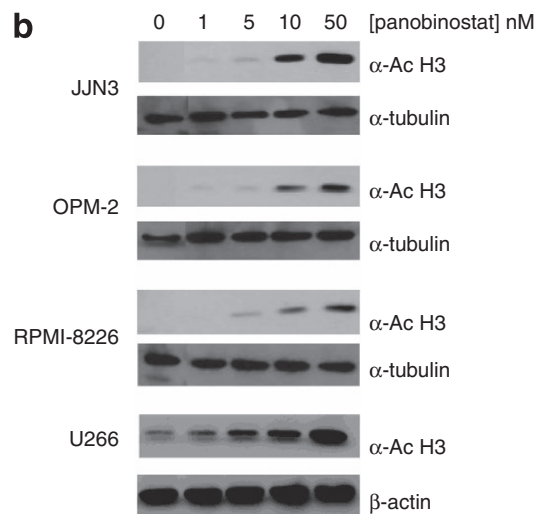

Figure 1 (a) Differential sensitivities of human MM cell lines to HDACi treatment. Single-agent dose-response curves constructed for each human MM cell line (JJN3, OPM-2, RPMI-8226 and U266) treated with vorinostat, panobinostat or romidepsin for 24 and $48 \mathrm{~h}$. (b) On-target histone-H3 acetylation is demonstrated in a dose-dependent manner in human MM cell lines (JJN3, OPM-2, RPMI-8226 and U266) treated for $24 \mathrm{~h}$ with increasing doses of panobinostat $(0,15,10$ and $50 \mathrm{nM})$ and assessed by western blot

in response to TRAIL $\left(\mathrm{EC}_{50}=27 \mathrm{ng} / \mathrm{ml}\right)$. For the other $\mathrm{MM}$ cell lines expressing low levels of DR-4/5, DR-4 expression was higher in the OPM-2 cell line and more closely correlated with rhTRAIL sensitivity $\left(\mathrm{EC}_{50}=60 \mathrm{ng} / \mathrm{ml} ; 48 \mathrm{~h}\right)$. Combining panobinostat with rhTRAIL synergistically induced apoptosis in RPMI-8226 and U266 cells. This combination induced 
a

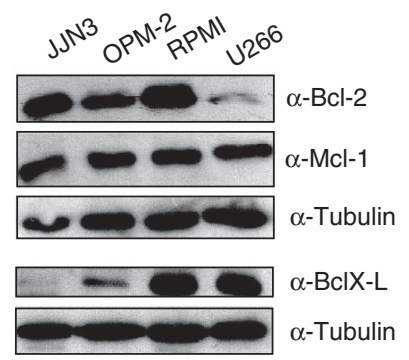

b JJN3

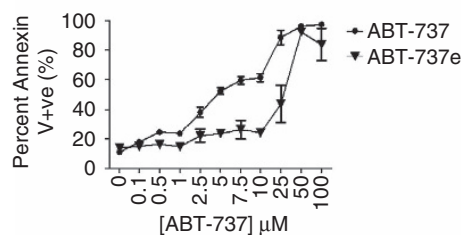

OPM-2
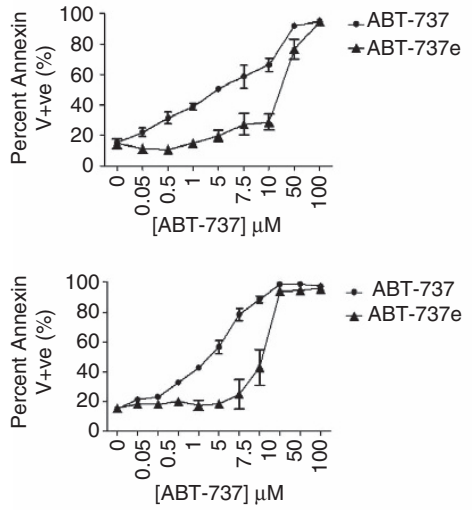

U266

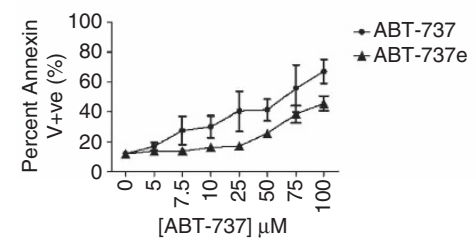

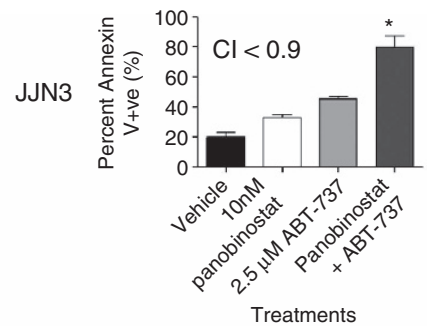

OPM-2

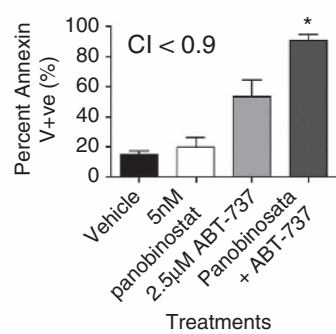

RPMI-8226

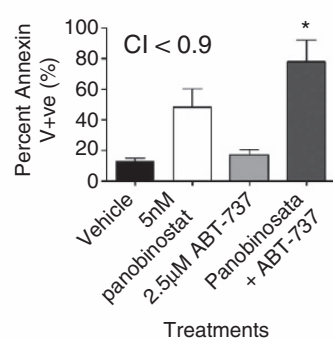

U266

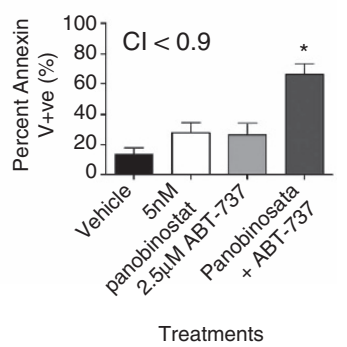

Figure 2 (a) Human MM cell lines demonstrate differential expression of Bcl-2 prosurvival proteins. JJN3, OPM-2, RPMI-8226 and U266 were assessed for the expression of antiapoptotic Bcl-2 proteins by western blot: Bcl-2, Bcl-X , Bcl-W, Mcl-1 and A1. (b) Differential sensitivities of human MM cell lines to ABT-737. Single-agent dose-response curves were constructed in human MM cell lines (JJN3, OPM-2, RPMI-8226 and U266) treated with ABT-737 for 24 and $48 \mathrm{~h}$. (c) Synergistic induction of apoptosis in human MM cell lines JJN3, OPM-2, RPMI-8226 and U266 following $48 \mathrm{~h}$ treatment with panobinostat in combination with ABT-737 after $48 \mathrm{~h}$ incubation. ${ }^{*} P<0.05$ versus single agents. Calcusyn was used to determine synergy when the two agents were combined: synergy is determined when $\mathrm{Cl}<0.9$, additively when $\mathrm{Cl}$ is between 0.9 and 1.1 and antagonism when $\mathrm{Cl}>1.1$. $\mathrm{Cl}$ values are shown on each graph

additive levels of death in OPM-2 cells, whereas JJN3 cells remained relatively resistant to the combination (Figure $3 \mathrm{c}$ and Supplementary Figures $2 \mathrm{E}-\mathrm{H}$ ).

To elucidate mechanisms enabling HDACi to sensitize MM cells to rhTRAIL, panobinostat-treated cells were assessed for changes in cytosolic Flice-like inhibitory protein (c-FLIP $)$ (Figures $3 d$ and $e$ ) and DR-4/5 expression (Figure 3e). c-FLIP mRNA and protein expression (C-FLIP $\mathrm{L}_{\mathrm{L}}$ ) was reduced in a celland dose-dependent manner in all MM cell lines following 8 or $16 \mathrm{~h}$ treatment (Figures $3 \mathrm{~d}$ and e). Panobinostat increased DR-5 expression on RPMI-8226 cells but appeared to reduce DR-4 expression on U266 cells (Figure 3e). These data suggest that HDACi may sensitize MM cells to rhTRAILinduced apoptosis by the upregulation of DR-5 and/or suppression of C-FLIP $\mathrm{P}_{\mathrm{L}}$ in a cell- and dose-dependent manner.
MM cell apoptosis is enhanced by combining HDACi with 5-AZA. JJN3 and U266 cell lines with the highest and lowest sensitivity to panobinostat, respectively, were selected to investigate the potential for panobinostat to synergize with 5-AZA. JJN3 cells demonstrated dosedependent sensitivities to 5-AZA treatment (Figure 4a) that synergized with panobinostat (Figure $4 \mathrm{~b}$ and Supplementary Figures $2 \mathrm{I}-\mathrm{J}$ ) to induce rapid and robust cell death. U266 cells appeared relatively resistant to 5-AZA (Figure 4a); however, when combined with panobinostat, apoptosis increased greater than either agent alone (Figure 4b). RNA sequencing revealed significant changes (false discovery rate (FDR) <0.05) to the expression of approximately $20 \%, 4 \%$ and $22 \%$ of analyzed genes (18000) in JJN3 and $14 \%, 5 \%$ and $21 \%$ in U266 by panobinostat, 5 -AZA or the 
a
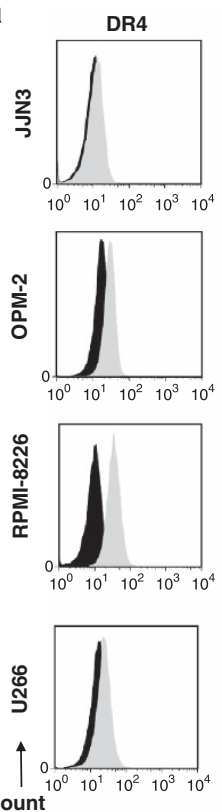

Count

DR-4/5-PE $\longrightarrow$
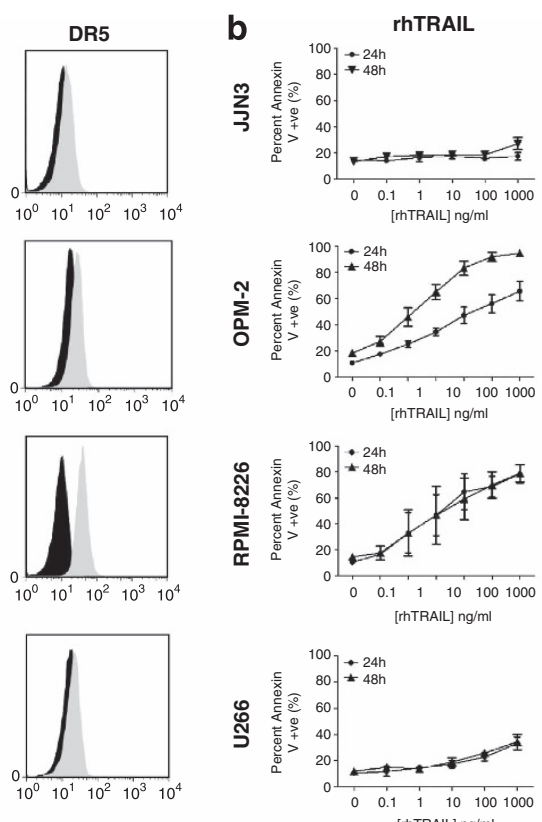

[rhTRAIL] ng/

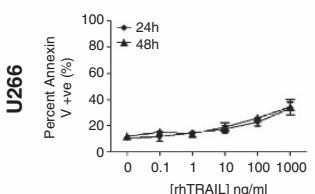

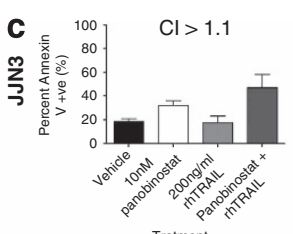

Tratment
$\mathrm{Cl}>0.9$
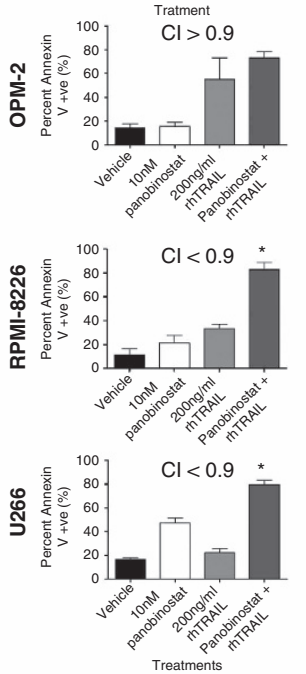

f
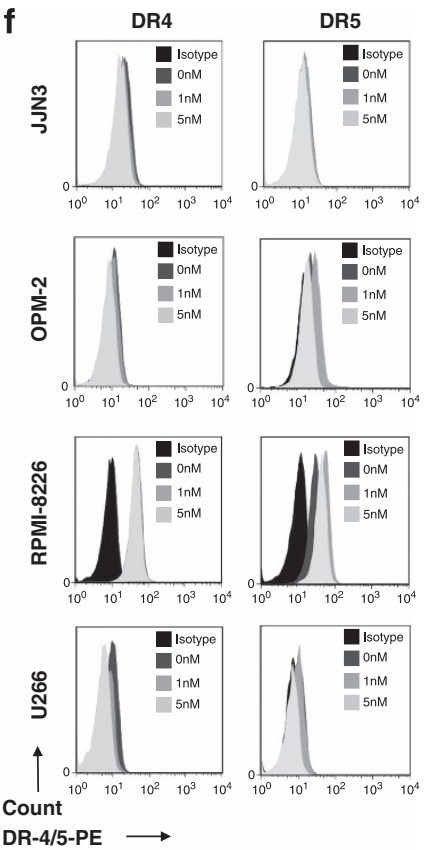

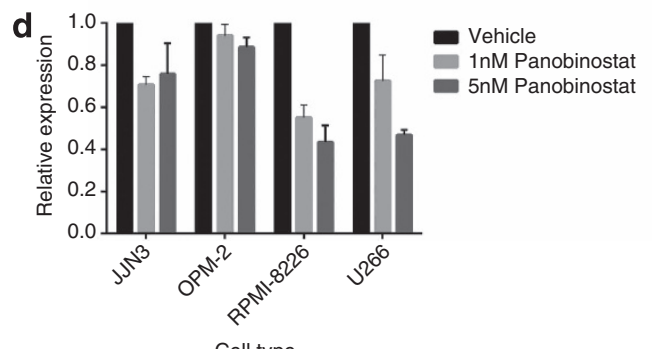

e JJN3
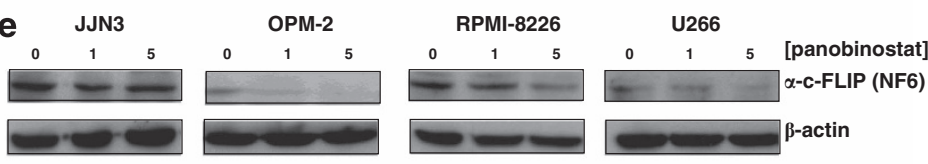

Figure 3 (a) Assessment of cell surface death receptor DR-4 and DR-5 on human MM cell lines JJN3, OPM-2, RPMI-8226 and U266, using flow cytometry against an isotype control antibody $(n=3)$. Black histogram = isotype control; gray shaded histogram $=$ DR4 or DR5 expression. (b) Differential sensitivities of human MM cell lines to rhTRAIL treatment. Single-agent dose-response curves were constructed in human MM cell lines (JJN3, OPM-2, RPMI-8226 and U266) treated with rhTRAIL for 24 and $48 \mathrm{~h}$. (c) Synergistic induction of apoptosis in human MM cell lines OPM-2, RPMI-8226 and U266 following $48 \mathrm{~h}$ treatment with panobinostat and rhTRAIL (Cl<0.9). The combination of panobinostat with rhTRAIL did not synergize in JJN3 cells $(\mathrm{Cl}>1.1)$ and was only additive in OPM-2 cells ( $\mathrm{Cl}$ between 0.9 and 1.1$)$. ${ }^{*} P<0.05$ versus single agents; analysis of c-FLIP (NF6) was undertaken in human MM cell lines (JJN3, OPM-2, RPMI-8226 and U266) following 8-16 h treatment with increasing doses of panobinostat below that shown to induce apoptosis $(0,1$ and $5 \mathrm{nM})$. (d) Panobinostat significantly reduced c-FLIP mRNA expression levels in all cell types $(8 \mathrm{~h})$, whereas (e) protein expression was reduced in OPM-2, RPMI-8226 and U266 cells (16h); and (f) assessment of cell surface DR-4/5 expression on human MM cell lines (JJN3, OPM-2, RPMI-8226 and U266) following treatment ( $16 \mathrm{~h}$ ) with panobinostat $(n=3)$. Panobinostat treatment significantly increased DR-5 expression on RPMI-8226 cells while appearing to reduce DR-4 expression on U266 cells $(P<0.05)$. Black histogram $=$ isotype control; dark gray shaded histogram $=$ vehicle control; medium shade of gray histogram $=1 \mathrm{nM}$ panobinostat; light shade of gray histogram $=5 \mathrm{nM}$ panobinostat. At least $n=3$ biological replicates were carried out for each assessment

combination of both agents, respectively (data not shown). Specifically, panobinostat reproducibly lowered the transcription of IL-6, IL-6R and IL-6 signal transducer in both cell types, whereas 5-AZA reduced IL-6 transcription in U266 cells only. Combination treatment further reduced IL- 6 in U266 cells only. Taken together, the reduced expression of IL-6 was not a common effect of combination therapy and unlikely to facilitate drug synergy in both cell lines.

Gene set enrichment analysis utilizing CAMERA (correlation adjusted mean rank) ${ }^{40}$ revealed distinct molecular signatures when JJN3 and U266 cells were treated with combination therapies not seen during single-agent dosing (Figures $4 c$ and d) (Tables 1a and b). We purport that the greater number of unique gene sets affected by combination therapy in JJN3 cells, which include relevant $\mathrm{HDACi}$, methylation and $\mathrm{MM}$ signaling pathways may reflect the greater induction of apoptosis in this MM cell line than U266. In addition, we observed upregulation of a single gene set signature common to both cell lines that was unique to the combination therapy (Figure 4e and Table 1c). This suggests that activation of cell-line-specific molecular signatures may enable amplification of the synergistic apoptotic response when panobinostat and 5-AZA were combined.

Preclinical assessment of HDACi with ABT-737, MD5-1 or 5-AZA in Vk*MYC MM. We used the Vk* MYC model to test efficacy and tolerability of combining $\mathrm{HDACi}$ with ABT-737, MD5-1 an agonistic antibody against mouse DR-5 or 5-AZA. The expression of prosurvival $\mathrm{Bcl}-2$ proteins and DR-5 was assessed by western blot and flow cytometry, 
a
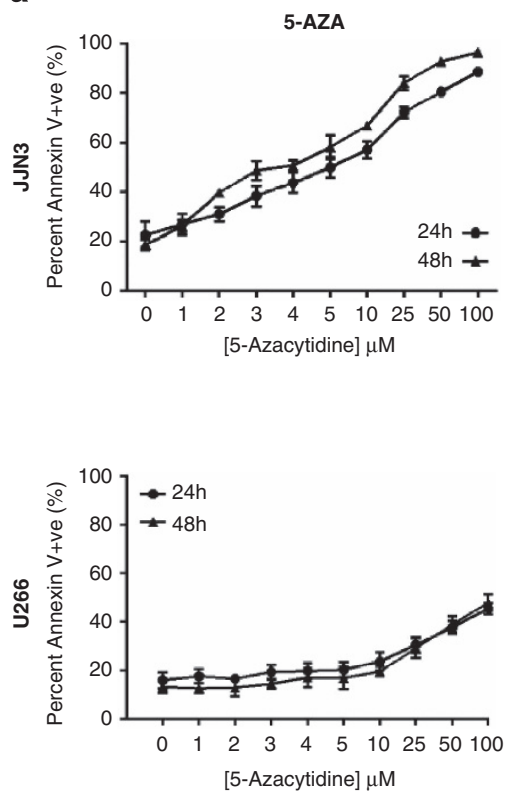

b
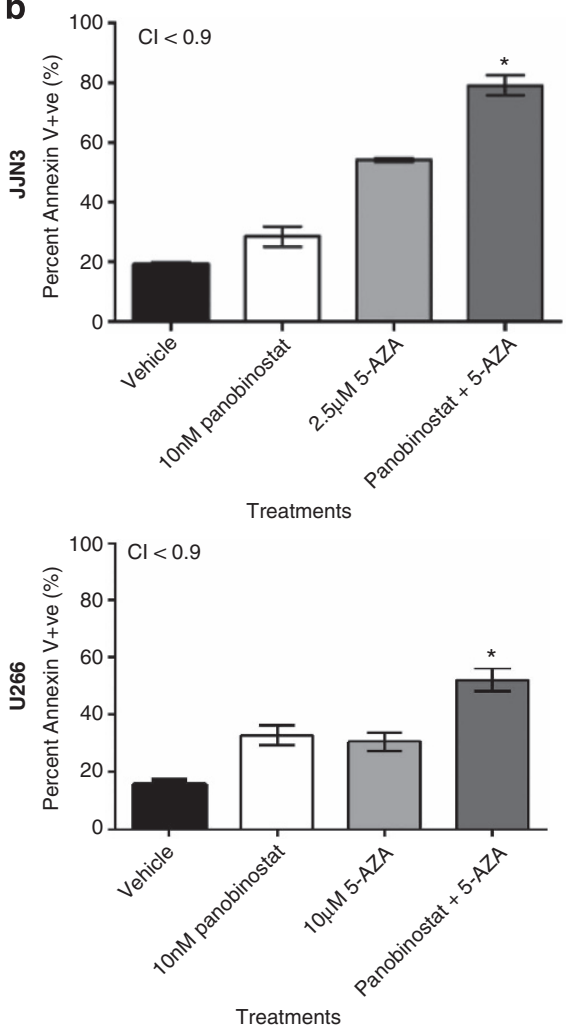
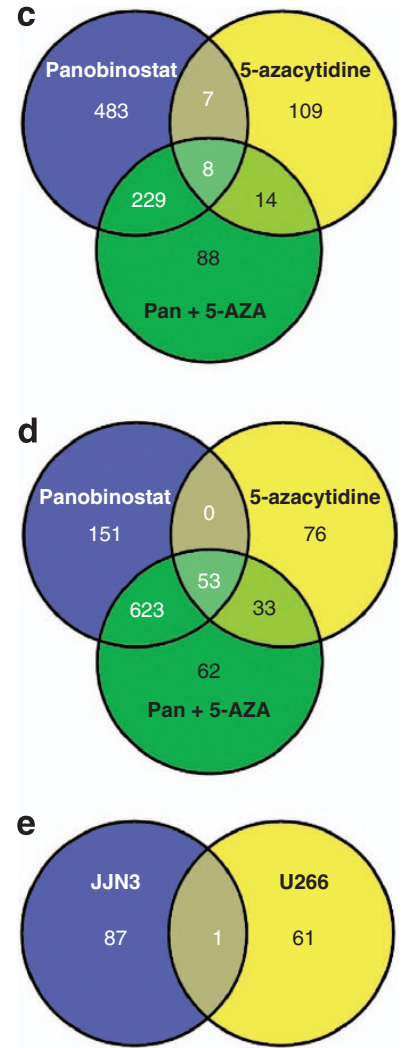

Figure 4 (a) Human MM cell lines display differential and dose-dependent sensitivities to 5-AZA. Single-agent dose-response curves were constructed in human MM cell lines (JJN3 and U266) treated with 5-AZA for 24 and $48 \mathrm{~h}$. (b) Synergistic induction of apoptosis in JJN3 and U266 cells with panobinostat was combined with 5-AZA after 48 $\mathrm{h}$ $(\mathrm{Cl}<0.9){ }^{*} P<0.05$ verses single agents: (c) JJN3 cells or (d) U266 cells were treated with panobinostat, 5-AZA or the combination of both agents at synergistic concentrations (described in Figure 4b) and assessed for changes in gene expression using next-generation RNA sequencing after $24 \mathrm{~h}$. Gene set enrichment was assessed using CAMERA. ${ }^{40}$ Each Venn diagram depicts the number of MSigDB gene sets enriched within each treatment and within each cell line (two-sided $\left.P<0.05, n=3\right) ;(e)$ demonstrates the number of distinct or overlapping MSigDB gene sets enriched when JJN3 or U266 cells were treated with the combination of panobinostat with 5-AZA

respectively (Figure 5). Primary Vk*MYC MM cells expressed Bcl-2, Bcl- $\mathrm{X}_{\mathrm{L}}$ and Mcl-1 (Figure 5a) but not Bcl-w (data not shown), whereas FACS analysis confirmed the expression of mDR-5 on B220 - /CD138 + plasma cells (Figure 5b).

Mice bearing Vk*MYC tumor were treated with vehicle, panobinostat $(25 \mathrm{mg} / \mathrm{kg}$ then $15 \mathrm{mg} / \mathrm{kg})$, ABT-737 $(75 \mathrm{mg} / \mathrm{kg})$ or the combination of agents. This resulted in significant reductions in serum paraprotein over the period of therapy, resulting in a significant survival advantage in mice treated with panobinostat alone (median $>25$ days) compared with vehicle control (median $=14$ days, $P<0.05$ ) (Figures $6 a$ and b). In contrast, single-agent ABT-737 had neither effect on serum paraprotein nor the survival of mice bearing $\mathrm{Vk}^{\star} \mathrm{MYC}$ MM (median=11 days). Unfortunately, although serum paraprotein was significantly reduced (data not shown), the combination of panobinostat with ABT-737 led to all mice reaching end points by day 3 of treatment, putatively because of drug-induced toxicity (Figures $6 a$ and b). Mice bearing Vk*MYC tumors were then treated with vehicle, low-dose panobinostat $(5 \mathrm{mg} / \mathrm{kg})$, ABT-737 $(50 \mathrm{mg} / \mathrm{kg})$ or the combination. The dose of panobinostat used was the maximumtolerated dose when combined with ABT-737 (data not shown). Panobinostat significantly reduced paraprotein levels compared with vehicle-treated control levels (day 26,
$P<0.05)$, whereas ABT-737 had no significant effect $(P>0.05)$ over the period of therapy (Figure $6 \mathrm{c})$. Therefore, in contrast to in vitro data, combining both agents had no additional effect on serum paraprotein levels achieved by panobinostat treatment alone $(P>0.05)$ and no survival advantage was observed using the combination regimen (Figure 6d).

Mice bearing $\mathrm{Vk}^{*} \mathrm{MYC}$ tumor were treated with vehicle, panobinostat, MD5-1 and the combination. A significant reduction in serum paraprotein was observed after 5 days of panobinostat treatment, and further reduced in mice receiving combination treatment compared with vehicle controls (Figures $7 \mathrm{a}, P<0.05$ ). No change to serum paraprotein levels were observed with mice receiving MD5-1 treatment at this time $(P>0.05)$. Survival of mice receiving panobinostat alone was significantly increased compared with vehicle-treated mice (median $=40$ versus 26.5 days, $P<0.05$ ) (Figure $7 \mathrm{~b}$ ). In contrast, MD5-1-treated mice showed no survival benefit over mice treated with vehicle (median $=24$ versus 26.5 days; $P>0.05)$, whereas all mice receiving combination therapy reached end points by day 10 . These early deaths occurred in the combination treatment group despite significant reductions in tumor burden as assessed by reduction in serum paraprotein, indicating mortality due to drug toxicity 
Table 1a Molecular signatures unique to the panobinostat and 5-AZA combination in JJN3 cells (Figure 4e)

\begin{tabular}{|c|c|c|c|c|}
\hline Gene set & $\begin{array}{l}\text { No. of } \\
\text { genes }\end{array}$ & Direction & $\begin{array}{c}\text { Two-sided } \\
P \text {-value }\end{array}$ & FDR \\
\hline JISON SICKLE CELL DISEASE DN & 151 & Down & 0.006 & 0.491 \\
\hline CHEOK_RESPŌNSE_TO_MERCAPTOPURINE_DN & 16 & Up & 0.003 & 0.491 \\
\hline SATO_SILENCED_BY $M \bar{E} T H Y L A T I O N$ IN_PANCREATIC_CANCER_2 & 30 & Up & 0.003 & 0.491 \\
\hline MIKKELSEN IPS HCP WITH H3 UNMETHYLATED & 36 & Up & 0.012 & 0.491 \\
\hline KIM_RESPONSE_TO_TSA_AND_DECITABINE_UP & 90 & Up & 0.016 & 0.491 \\
\hline MCGARVEY SILENCED BY METHYLATION IN COLON CANCER & 25 & Up & 0.017 & 0.491 \\
\hline BIOCARTA UCALPAIN_PATHWAY & 16 & Up & 0.017 & 0.491 \\
\hline NUMATA CSF3 SIGNALING VIA STAT3 & 17 & Down & 0.019 & 0.491 \\
\hline KIM WT1 TARGETS $12 \mathrm{HR}$ DN & 177 & Down & 0.019 & 0.491 \\
\hline KUNINGER_IGF1_VS_PDGFB_TARGETS_UP & 47 & Up & 0.020 & 0.491 \\
\hline LABBE TGFB1 TARGETS UP & 80 & Up & 0.020 & 0.491 \\
\hline SATO SILENCED EPIGENETICALLY IN PANCREATIC CANCER & 32 & Up & 0.021 & 0.491 \\
\hline APPEL_IMATINIB_RESPONSE & 26 & Up & 0.021 & 0.491 \\
\hline LEE_LIVER_CANC̄ER_CIPROFIBRATE_UP & 37 & Up & 0.023 & 0.491 \\
\hline PID ECADHERIN KERATINOCYTE PATHWAY & 18 & Up & 0.025 & 0.491 \\
\hline REACTOME_TRAFFICKING_OF_AMPA_RECEPTORS & 19 & Up & 0.026 & 0.491 \\
\hline KEGG_N_GLYCAN_BIOSYNTHESIS & 44 & Down & 0.027 & 0.491 \\
\hline KUNINGER IGF1 VS PDGFB TARGETS DN & 35 & Up & 0.027 & 0.491 \\
\hline ZHAN MULTIPLE MYELOMA CD2 DN & 45 & Down & 0.027 & 0.491 \\
\hline AIGNER ZEB1 TARGETS & 23 & Up & 0.028 & 0.491 \\
\hline REACTOME_CELL_JUNCTION_ORGANIZATION & 54 & Up & 0.028 & 0.491 \\
\hline KEGG_TIGHT_JUNCTION & 107 & Up & 0.029 & 0.491 \\
\hline VERRECCCHIA RESPONSE TO TGFB1 C2 & 24 & Up & 0.029 & 0.491 \\
\hline REACTOME SEMA4D IN SEMAPHORIN SIGNALING & 29 & Up & 0.029 & 0.491 \\
\hline HELLER_SILENCED_BY METHYLATION_UP & 224 & Up & 0.029 & 0.491 \\
\hline BIOCARTA FAS PATHWAY & 29 & Down & 0.030 & 0.491 \\
\hline REACTOME_G1_PHASE & 35 & Down & 0.030 & 0.491 \\
\hline MEISSNER_BRAIN_HCP_WITH_H3K4ME2_AND_H3K27ME3 & 40 & Up & 0.030 & 0.491 \\
\hline PID HIVNEFPATHWAY & 32 & Down & 0.031 & 0.491 \\
\hline REACTOME SEMA4D INDUCED CELL MIGRATION AND GROWTH CONE COLLAPSE & 25 & Up & 0.032 & 0.491 \\
\hline SHIN B CELL LYMPHOMA CLUSTER 2 & 27 & Down & 0.032 & 0.491 \\
\hline ZWANG_CLASS_2_TRANSIENTLY_INDUUCED_BY_EGF & 34 & Up & 0.032 & 0.491 \\
\hline JOHANSSON GLIOMAGENESIS BY PDGFB DN & 18 & Up & 0.033 & 0.491 \\
\hline REACTOME STRIATED MUSCLE CONTRACTION & 18 & Up & 0.034 & 0.491 \\
\hline LIANG_SILENCEED_BY_METHYLATION_2 & 35 & Up & 0.034 & 0.491 \\
\hline BIOCARTA ARF PATHWAY & 17 & Down & 0.034 & 0.491 \\
\hline BACOLOD RESISTANCE TO ALKYLATING AGENTS UP & 20 & Up & 0.034 & 0.491 \\
\hline CREIGHTON_ENDOCRINE_THERAPY_RESISTANCE_2 & 389 & Up & 0.035 & 0.491 \\
\hline REACTOME_CELL_CELL_COMMUNICATTION & 87 & Up & 0.035 & 0.491 \\
\hline REACTOME AXON GUIDANCE & 207 & Up & 0.035 & 0.491 \\
\hline BRACHAT RESPONSE TO METHOTREXATE UP & 23 & Up & 0.035 & 0.491 \\
\hline RAMPON_ENRICHED_LEARNING_ENVIRONMENT_LATE_UP & 19 & Down & 0.036 & 0.491 \\
\hline MIPS $28 \mathrm{~S}$ RIBOSOMAL SUBUNIT MITOCHONDRIAL & 30 & Down & 0.036 & 0.491 \\
\hline KEGG_FOCAL_ADHESIŌN & 168 & Up & 0.036 & 0.491 \\
\hline REACTOME RECYCLING PATHWAY OF L1 & 26 & Up & 0.037 & 0.491 \\
\hline HAHTOLA_MYCOSIS_FUNGOIDES_CD4_DN & 112 & Down & 0.037 & 0.491 \\
\hline MCBRYAN PUBERTAL TGFB1 TARGETS DN & 41 & Up & 0.038 & 0.491 \\
\hline CLASPER LYMPHATIC VESSELS DURING METASTASIS UP & 16 & Up & 0.038 & 0.491 \\
\hline MATZUK_SPERMATOZŌA & 81 & Up & 0.038 & 0.491 \\
\hline MARTENS TRETINOIN RESPONSE UP & 377 & Up & 0.038 & 0.491 \\
\hline MOREAUX B LYMPHOCYTE MATURATION BY TACI UP & 70 & Up & 0.039 & 0.491 \\
\hline DORSEY GAB2 TARGETS & 22 & Up & 0.039 & 0.491 \\
\hline LIAN_LIPA_TARGETS $6 \mathrm{M}$ & 34 & Up & 0.039 & 0.491 \\
\hline VANTVEER BREAST CANCER BRCA1 UP & 32 & Down & 0.040 & 0.491 \\
\hline MISSIAGLIA REGULATED BY METHYLATION UP & 102 & Up & 0.041 & 0.491 \\
\hline MIPS 55S RIBOSOME MITOCHONDRIAL & 77 & Down & 0.041 & 0.491 \\
\hline VALK_AML_CLUSTER_15 & 23 & Up & 0.042 & 0.491 \\
\hline REACTOME MITOCHONDRIAL TRNA AMINOACYLATION & 20 & Down & 0.042 & 0.491 \\
\hline CHIANG LIVER CANCER SUBCLASS POLYSOMY7 UP & 55 & Up & 0.042 & 0.491 \\
\hline SATO_SILENCED_BY_METHYLATION_IN_PANCREATIC_CANCER_1 & 286 & Up & 0.042 & 0.491 \\
\hline BIOCARTA AGR PATHWAY & 27 & Up & 0.042 & 0.491 \\
\hline CROONQUIST STROMAL STIMULATION UP & 45 & Up & 0.043 & 0.491 \\
\hline NIELSEN SYNOVIAL SARCOMA UP & 15 & Up & 0.043 & 0.491 \\
\hline HUANG_GATA2_TARGETS_DN & 62 & Down & 0.043 & 0.491 \\
\hline KEGG LEUKOCYTE TRANSENDOTHELIAL MIGRATION & 91 & Up & 0.044 & 0.491 \\
\hline ONKEN_UVEAL_MELANOMA_UP & 731 & Down & 0.045 & 0.491 \\
\hline PID S1P S1P1 PATHWAY & 19 & Up & 0.045 & 0.491 \\
\hline YAO TEMPORAL RESPONSE TO PROGESTERONE CLUSTER 1 & 59 & Up & 0.045 & 0.491 \\
\hline ZHAN̄G TLX TARGETS DN & 91 & Up & 0.046 & 0.491 \\
\hline GU PDEF TARGETS DN & 25 & Up & 0.046 & 0.491 \\
\hline ZHÖNG_RESPONSE_TO_AZACITIDINE_AND_TSA_DN & 64 & Down & 0.047 & 0.491 \\
\hline VILIMAS NOTCH 1 TARGETS UP & 39 & Up & 0.047 & 0.491 \\
\hline
\end{tabular}


Table 1a (Continued)

\begin{tabular}{|c|c|c|c|c|}
\hline Gene set & $\begin{array}{l}\text { No. of } \\
\text { genes }\end{array}$ & Direction & $\begin{array}{l}\text { Two-sided } \\
P \text {-value }\end{array}$ & FDR \\
\hline BURTON ADIPOGENESIS 7 & 41 & Up & 0.047 & 0.491 \\
\hline PID_INTËGRIN_A9B1_PATHWAY & 17 & Up & 0.047 & 0.491 \\
\hline REACTOME_CELL_SURFACE_INTERACTIONS_AT_THE_VASCULAR_WALL & 62 & Up & 0.048 & 0.491 \\
\hline ZHONG_RESPONSE_TO_AZACITIDINE_AND_TSA_UP & 162 & Up & 0.048 & 0.491 \\
\hline BAELDE DIABETIC NEPHROPATHY UP & 56 & Up & 0.048 & 0.491 \\
\hline MULLIGAN_NTF3_SIGNALING_VIA_INSR_AND_IGF1R_UP & 18 & Down & 0.048 & 0.491 \\
\hline BRACHAT_RESPONSE_TO_CAMPTOTHECIN_ÜP & 26 & Up & 0.049 & 0.491 \\
\hline $\begin{array}{l}\text { REACTOME_NEF_MEDIATES_DOWN_MODULATION_OF_CELL_SURFACE_RECEPTORS_ } \\
\text { BY_RECRUITING_THEM_TO_CLATHRIN_ADAPTERS }\end{array}$ & 16 & Up & 0.049 & 0.491 \\
\hline POTTIICYTOXAN_SENSITIVITY & 30 & Up & 0.049 & 0.491 \\
\hline GOLUB_ALL_VS_AML_DN & 18 & Up & 0.049 & 0.491 \\
\hline MIPS_39S_RIBOSOMAL_SUBUNIT_MITOCHONDRIAL & 47 & Down & 0.049 & 0.491 \\
\hline KIM_MYYC_AMPLIFICATION_TARGETTS_UP & 169 & Down & 0.049 & 0.491 \\
\hline LIN_SILENCED_BY_TUMOR_MICROENVIRONMENT & 67 & Up & 0.049 & 0.491 \\
\hline PID THROMBIN PAR 1 PATHWAY & 37 & Up & 0.049 & 0.491 \\
\hline CHIANG LIVER CANCER SUBCLASS INTERFERON DN & 42 & Up & 0.049 & 0.491 \\
\hline
\end{tabular}

CAMERA results for the gene sets from the MSigDB from panobinostat- and 5-AZA-treated JJN3 cells. Data include the size of each set, direction of gene set alterations, two-sided $P$-value and FDR

rather than disease progression. In an attempt to overcome the toxicities observed, the dose of panobinostat was reduced. Treatment with panobinostat alone $(7.5 \mathrm{mg} / \mathrm{kg})$ led to significant reductions in serum paraprotein $(P<0.05)$, whereas MD5-1 alone, and its combination with panobinostat, had no significant effect $(P>0.05)$ (Figure 7c). Treatment with panobinostat resulted in an increase in survival of tumorbearing mice compared with vehicle treatment (median $=18$ versus 39 days, $P<0.05$ ), whereas MD5-1 had a marginal effect on mouse survival (median $=18$ versus 25 days, $P>0.05$ ) (Figure 7d). Interestingly, even with the reduced dosage of panobinostat, combination treatment with MD5-1 was still intolerable with mice succumbing earlier than vehicletreated mice (median $=18$ versus 15 days, $P>0.05$ ) (Figure 7d). Similar toxicities using the combination of panobinostat and MD5-1 were observed in mice bearing a second independently derived $\mathrm{Vk}^{\star} \mathrm{MYC}$ myeloma (data not shown).

To determine whether the toxicity of combined panobinostat/MD5-1 treatment was due to direct effects on host cells, the experiment was repeated using C57BL/6.DR5 ${ }^{-/-}$mice bearing transplanted $\mathrm{Vk}^{\star} \mathrm{MYC}$ tumor. Mice were treated with vehicle, panobinostat $(7.5 \mathrm{mg} / \mathrm{kg})$, MD5-1 $(50 \mu \mathrm{g}$ per mouse) and the combination of both agents. In contrast to experiments in wild-type mice, no dose-limiting toxicity was observed (Figure 7e). As shown previously, MD5-1 treatment alone had no effect on survival compared with control-treated mice (median $=27.5$ versus 30.5 days, $P>0.05$ ), whereas panobinostat alone significantly increased the median survival time (median $=39.5$ days, $P<0.05$ ). Remarkably, in the absence of on-target toxicity, the combination of panobinostat and MD5-1 provided the greatest survival advantage in tumor-bearing $\mathrm{C} 57 \mathrm{BL} / 6 . \mathrm{DR} 5^{-1-}$ mice with a significant increase in survival compared with vehicle-treated mice (median $=54$ versus 30.5 days; $P<0.05$ ) (Figure $7 \mathrm{e}$ ).

Finally, mice bearing $\mathrm{Vk}^{*} \mathrm{MYC}$ tumor were treated with vehicle, panobinostat, 5-AZA or the combination. After 12 days of treatment, a significant reduction in serum paraprotein was observed in panobinostat- and 5-AZA-treated mice that were further reduced when the two agents were combined (Figure 7f). Importantly, the combination of panobinostat with 5-AZA led to the greatest survival advantage in tumor-bearing mice over vehicle-treated mice, greater than doubling their survival time (median $=32$ versus 68.5 days; $P<0.05$ ) (Figure 7g).

\section{Discussion}

MM is an incurable malignancy with an unmet need for novel therapeutic agents. ${ }^{5}$ Here, we combined in vitro cell linebased profiling with in vivo pre-clinical screening utilizing syngeneic transplanted $\mathrm{Vk}^{\star} \mathrm{MYC}$ MM to investigate efficacy and safety of single-agent and combination therapies. HDACi were the primary agents under investigation and these were combined with ABT-737 targeting the intrinsic apoptosis pathway; rhTRAIL/MD5-1 that activates the extrinsic pathway or the DNMTi 5-AZA. We demonstrate that while in vitro studies provide some insight into drug combinations that synergistically kill MM cells, they do not guarantee their efficacy or tolerability in vivo. Our results provide evidence that $\mathrm{Vk}^{\star} \mathrm{MYC}$ MM may aid in predicting clinical utilization of novel therapies by eliminating ineffective drug combinations and identifying associated on-target toxicities. Moreover, we describe the potential for HDACi to synergize with agents inhibiting DNA methylation, such as 5-AZA, in MM.

Recent investigations have highlighted the potential for HDACi in the treatment of MM. ${ }^{41,42}$ Indeed, the $\mathrm{Vk}^{*} \mathrm{MYC}$ model has proven useful in predicting that the combination of HDACi with bortezomib would be safe and effective for the treatment of $\mathrm{MM}^{3}{ }^{35}$ Here, we demonstrated the induction of apoptosis in four human MM cell lines by vorinostat, panobinostat and romidepsin concomitant with on-target histone $\mathrm{H} 3$ acetylation. Owing to the low nanomolar activity of panobinostat in vitro and current phase III testing, this panHDACi was utilized in all further single-agent and combination experiments.

Previous investigators have suggested that the expression of prosurvival $\mathrm{Bcl}-2$ family proteins can determine HDACi 
Table 1b Molecular signatures unique to the panobinostat and 5-AZA combination in U266 cells (Figure 4e)

\begin{tabular}{|c|c|c|c|c|}
\hline Gene Set & $\begin{array}{l}\text { No. of } \\
\text { genes }\end{array}$ & Direction & $\begin{array}{c}\text { Two-sided } \\
P \text {-value }\end{array}$ & FDR \\
\hline KRASNOSELSKAYA ILF3 TARGETS DN & 39 & Down & 0.011 & 0.168 \\
\hline ISHIDA_E2F_TARGETTS & 52 & Down & 0.014 & 0.170 \\
\hline WU_APOPTŌSIS_BY_CDKN1A_VIA_TP53 & 53 & Down & 0.016 & 0.172 \\
\hline CHEMNITZ_RESPONS̄E_TO_PROSTAGLANDIN_E2_UP & 135 & Down & 0.018 & 0.179 \\
\hline REACTOMĒ_MEIOSIS & 61 & Down & 0.023 & 0.182 \\
\hline NUNODA_RĒSPONSE_TO_DASATINIB_IMATINIB_UP & 29 & Down & 0.025 & 0.186 \\
\hline RUIZ_TNC_TARGETS_DN & 131 & Down & 0.026 & 0.190 \\
\hline BIOCARTA NOS1 PATHWAY & 15 & Up & 0.027 & 0.191 \\
\hline BLUM_RESPONSĒ_TO_SALIRASIB_DN & 325 & Down & 0.028 & 0.193 \\
\hline YU_BĀP1_TARGETS & 28 & Down & 0.028 & 0.193 \\
\hline BERTUCCI_INVASIVE_CARCINOMA_DUCTAL_VS_LOBULAR_DN & 26 & Up & 0.029 & 0.197 \\
\hline $\begin{array}{l}\text { REACTOME_ACTIVATION_OF_NMDA_RECEPTOR_UPON_GLUTAMATE_ } \\
\text { BINDING_AND_POSTSYNAPTIC_EVENTS }\end{array}$ & 25 & Up & 0.031 & 0.201 \\
\hline MARTENS_TRETINOIN_RESPONSE_DN & 682 & Down & 0.032 & 0.202 \\
\hline REACTOME_FANCONI_ANEMIA_PATHWAY & 20 & Down & 0.033 & 0.203 \\
\hline REACTOME_ACTIVATIŌN_OF_THE_PRE_REPLICATIVE_COMPLEX & 28 & Down & 0.033 & 0.204 \\
\hline REACTOME_CREB_PHOSPHORYLATION_THROUGH_THE_ACTIVATION_OF_RAS & 19 & Up & 0.033 & 0.204 \\
\hline REACTOME_DNA_STRAND_ELONGATION & 29 & Down & 0.034 & 0.205 \\
\hline KORKOLA_EMBRYONIC_CARCINOMA_VS_SEMINOMA_DN & 18 & Up & 0.035 & 0.206 \\
\hline KYNG_WERNER_SYNDROM_UP & 20 & Up & 0.035 & 0.206 \\
\hline NOUSHMEHR_GBM_SILENCED_BY_METHYLATION & 36 & Up & 0.036 & 0.209 \\
\hline $\begin{array}{l}\text { REACTOME_DEPOSITION_OF_NEW_CENPA_CONTAINING_NUCLEOSOMES_ } \\
\text { AT THE CENTROMERE }\end{array}$ & 35 & Down & 0.036 & 0.209 \\
\hline NIELSEN_LIPOSARCOMA_DN & 17 & Up & 0.037 & 0.209 \\
\hline $\begin{array}{l}\text { REACTOME_HOMOLOGOUS_RECOMBINATION_REPAIR_OF_REPLICATION_ } \\
\text { INDEPENDENT DOUBLE STRAND BREAKS }\end{array}$ & 16 & Down & 0.037 & 0.209 \\
\hline REACTOME_POST_NMDA_RECEPTOR_ACTIVATION_EVENTS & 24 & Up & 0.037 & 0.209 \\
\hline MAHAJAN_RESPONESE_TO_IL1A_DN & 63 & Up & 0.038 & 0.210 \\
\hline KEGG_MELANOGENESIS & 74 & Up & 0.040 & 0.216 \\
\hline KEGG_ALDOSTERONE_REGULATED_SODIUM_REABSORPTION & 34 & Up & 0.040 & 0.216 \\
\hline JAZAERI_BREAST_CANCER_BRCA1_VS_BRCA2_DN & 38 & Up & 0.041 & 0.217 \\
\hline ST_T_CELL_SIGNĀL_TRANSDUCTION & 38 & Down & 0.041 & 0.217 \\
\hline LUİ_THYROIID_CANCER_CLUSTER_1 & 49 & Up & 0.041 & 0.218 \\
\hline GAR̄GALOVIC_RESPONSEE_TO_OXIDIZED_PHOSPHOLIPIDS_TURQUOISE_DN & 53 & Down & 0.042 & 0.221 \\
\hline IVANOVA_HEMATAOPOIESIS_STEM_CELL & 205 & Up & 0.043 & 0.222 \\
\hline BENPORATH_ES_2 & 29 & Down & 0.043 & 0.222 \\
\hline REACTOME_LAGGING_STRAND_SYNTHESIS & 18 & Down & 0.043 & 0.223 \\
\hline REACTOME_SYNTHESIS_OF_PC̄ & 16 & Up & 0.043 & 0.223 \\
\hline WAMUNYOKOLI_OVARIAN_CANCER_GRADES_1_2_DN & 53 & Up & 0.044 & 0.224 \\
\hline LINDGREN_BLADDER_CANCER_CLUSTER_3_UPP & 307 & Down & 0.044 & 0.225 \\
\hline REACTOMĒ_EXTENSIŌN_OF_TĒLOMERES $\overline{-}-{ }^{-}$ & 25 & Down & 0.045 & 0.226 \\
\hline LINDGREN_BLADDER_CANCĒR_CLUSTER_1_DN & 336 & Down & 0.045 & 0.226 \\
\hline AUNG_GASTRIC_CANCER & 39 & Down & 0.045 & 0.227 \\
\hline CASOREELLI_APL_SECONDARY_VS_DE_NOVO_UP & 34 & Up & 0.045 & 0.227 \\
\hline KEGG_BASĒ_EXC̄ISION_REPAIR & 32 & Down & 0.045 & 0.227 \\
\hline PID_WNT_NONCANONICAL_PATHWAY & 30 & Up & 0.046 & 0.227 \\
\hline TONKS_TARGETS_OF_RUNX1_RUNX1T1_FUSION_GRANULOCYTE_UP & 46 & Up & 0.046 & 0.227 \\
\hline PID_SYNNDECAN_2_PATTHWAY-- & 25 & Up & 0.046 & 0.227 \\
\hline STAEGE_EWING_FAMILY_TUMOR & 21 & Up & 0.046 & 0.227 \\
\hline REACTOME_SIGN̄ALING_BYY_NOTCH1 & 66 & Up & 0.046 & 0.227 \\
\hline CHANG_IMMORTALIZED_BY_HPV31_UP & 63 & Up & 0.046 & 0.227 \\
\hline REACTŌME_PYRIMIDINĒ_MĒTABOLİSM & 18 & Down & 0.046 & 0.227 \\
\hline PAL_PRMT5_TARGETS_UP & 187 & Down & 0.046 & 0.227 \\
\hline REACTOME_MEIOTIC_RECOMBINATION & 36 & Down & 0.047 & 0.228 \\
\hline BIOCARTA_C̄ELLCYCLËE_PATHWAY & 23 & Down & 0.048 & 0.228 \\
\hline KEGG_FC_GAMMA_R_MEDIATED_PHAGOCYTOSIS & 85 & Up & 0.048 & 0.229 \\
\hline CHICAS_RB1_TARGETS_LOW_SERUM & 86 & Down & 0.048 & 0.229 \\
\hline SPIELMĀN_LYYMPHOBLAST_EÜROPEAN_VS_ASIAN_UP & 451 & Down & 0.048 & 0.229 \\
\hline REACTOMĒ_RECRUITMENT̄_OF_MITOTIIC_CENTROSOME_PROTEINS_AND_COMPLEXES & 63 & Down & 0.049 & 0.231 \\
\hline KEGG_WNT_SIGNALING_PATHWWAY & 123 & Up & 0.049 & 0.231 \\
\hline HELLER_HDĀC_TARGETS__DN & 279 & Down & 0.049 & 0.231 \\
\hline REACTOME_GLYYCEROPHŌSPHOLIPID_BIOSYNTHESIS & 69 & Up & 0.049 & 0.231 \\
\hline SESTO_RESPONSE_TO_UV_C8 & 66 & Up & 0.049 & 0.231 \\
\hline RODRIGUUES_THYRŌID_CARCINOMA_UP & 15 & Down & 0.049 & 0.232 \\
\hline
\end{tabular}

CAMERA results for the gene sets from the MSigDB from panobinostat- and 5-AZA-treated U266 cells. Data include the size of each set, direction of gene set alterations, two-sided $P$-value and FDR

sensitivity. ${ }^{38,43,44}$ Therefore, we assessed $\mathrm{Bcl}-2$, Bcl- $\mathrm{X}_{\mathrm{L}}$, $\mathrm{Bcl}-\mathrm{w}, \mathrm{Mcl}-1$ and $\mathrm{A} 1$. Bcl-2 and $\mathrm{Bcl}-\mathrm{X}_{\mathrm{L}}$ expression levels were varied, whereas high levels of $\mathrm{Mcl}-1$ remained relatively constant between cell lines (Bcl-w and $\mathrm{A} 1$ were not detected). This suggests that expression of $\mathrm{Bcl}-2$ family proteins does not adequately predict sensitivity to panobinostat within 
Table 1c Molecular signature unique to the panobinostat and 5-azacytidine combination and common to JJN3 and U266 cells (Figure 4e)

\begin{tabular}{lccrr}
\hline Gene set & No. of genes & Direction & Two-sided $\boldsymbol{P}$-value & FDR \\
\hline REACTOME_L1CAM_INTERACTIONS & 72 & Up & 0.015 & 0.491 \\
& & Up & 0.048 \\
\hline
\end{tabular}

Overlapping CAMERA results for the gene sets from the MSigDB from panobinostat- and 5-AZA-treated JJN3 (top) and U266 (bottom) cells. Data include the size of each set, direction of gene set alterations, two-sided $P$-value and FDR

this study. However, expression of $\mathrm{Bcl}-2$ and $\mathrm{Bcl}-\mathrm{X}_{\mathrm{L}}$ in these MM cells provided a molecular rationale for testing the ability of ABT-737 to synergize with panobinostat. Combining panobinostat with $\mathrm{ABT}-737$ over a broad concentration range resulted in significant induction of apoptosis in all MM cell lines tested. The level of apoptosis induced was more than additive and most likely due to concomitant activation of the intrinsic death pathway by both agents. ${ }^{16,25}$ These in vitro results suggested the potential for this drug combination in treating MM.

A second therapy investigated, combining panobinostat with rhTRAIL, was based on the significant expression of death receptors DR-4 and DR-5 on two of the human MM cell lines tested. Previous investigators have documented the sensitivity of various MM cell lines to TRAIL-induced cell death, and the capability of HDACi to synergize with rhTRAIL through mechanisms including reactivation of silenced caspase-8, ${ }^{12}$ downregulation of C-FLIP ${ }^{12,27,45-47}$ and restoration of cell surface DR-4/5 expression. ${ }^{48}$ We demonstrated synergistic induction of apoptosis in OPM-2 and RPMI-8226 cells when panobinostat was combined with rhTRAIL. This marked synergism was also detected in U266 cells, which express very low levels of DR-4/5 and are insensitive to single-agent rhTRAIL. Furthermore, we observed that panobinostat treatment increased surface DR-5 expression and loss of $\mathrm{c}-\mathrm{FLIP}_{\mathrm{L}}$ in a cell line-dependent manner.

Previous studies investigating appropriate drug combinations for the treatment of MM have utilized human xenografts and immunodeficient mice. ${ }^{26,49,50}$ The $\mathrm{Vk}^{\star} \mathrm{MYC}$ model faithfully mimics human MM and provides a physiologically relevant tool for preclinical screening of novel therapeutics. $^{3,35}$ Transplanted $\mathrm{Vk}^{*} \mathrm{MYC} \mathrm{MM}$ enables testing of therapeutics in younger mice without the time and expense involved in aging de novo Vk*MYC mice. Utilizing wild-type C57BL/6 mice bearing Vk*MYC tumor cells, we demonstrated that although in vitro cell culture studies suggest that a drug combination might be effective, these in vitro studies do not always translate in vivo. As an example, while combined panobinostat and ABT-737 induced synergistic death of human $\mathrm{MM}$ cell lines in vitro, the combination was too toxic and provided no significant survival benefit over panobinostat alone when tested at the MTD in vivo. This is considering a large reduction in paraprotein levels detected in combination treated mice (day 3, data not shown). It is important to consider the biological consequences of interactions between MM cells and the microenvironment within the bone marrow niche that may protect against ABT-737-induced apoptosis. Indeed, ABT-737 and its analog ABT-263 show reduced efficacy against nodally based CLL cells compared with circulating disease. ${ }^{51,52}$ This might explain the divergent efficacy of ABT-737 against MM cell lines tested in vitro compared with $\mathrm{Vk}^{*} \mathrm{MYC} \mathrm{MM}$ cells resident in the transplanted host.

In contrast to the effects of ABT-737, the agonistic anti-DR5 monoclonal antibody MD5-1 synergized with HDACi to kill human $\mathrm{MM}$ cell lines in vitro and induce myeloma regressions in vivo. However, this was achieved at the expense of prohibitive on-target in vivo toxicity conferred by the combination regimen. Importantly, the efficacy of combined panobinostat and MD5-1 could be maintained in the absence of toxicity in DR-5 knockout recipient mice in agreement with our previous studies. ${ }^{17}$ Therefore, combined rhTRAIL/HDACibased strategies may be used to overcome MM drug resistance in the human setting, if dose-limiting toxicities can be managed.

Profiling drug combinations using in vitro cell line-based investigations and $\mathrm{Vk}^{\star} \mathrm{MYC} \mathrm{MM}$ highlighted synergy when panobinostat is combined with 5-AZA. RNA sequencing of human MM cell lines JJN3 and U266 highlight distinct molecular signatures that may explain the potent cell line-dependent synergies seen when the two agents are combined. Importantly, our results suggest that targeting the epigenome through two molecularly distinct mechanisms, by coadministration of HDACi and DNMTi, has the ability to enhance the sensitivity of MM cells to apoptosis induction, leading to greater survival in mice bearing Vk*MYC MM.

These comprehensive studies into combination therapies consisting of panobinostat with ABT-737, rhTRAIL/MD5-1 or 5-AZA demonstrate the potential for $\mathrm{Vk}^{*} \mathrm{MYC} \mathrm{MM}$ as a preclinical screening tool. In line with our recent publication, ${ }^{35}$ we clearly demonstrate that panobinostat treatment provides a significant survival advantage with even relatively low dosages of drug. Importantly, the use of Vk*MYC MM allowed us to document the lack of activity of ABT-737 when combined with panobinostat and identify a toxicity profile observed following combination of panobinostat with MD5-1 that restricts efficacious dosing of this dual treatment regimen. Remarkably, we report the synergistic induction of apoptosis in vitro when panobinostat is combined with 5-AZA that is demonstrated by significant reductions to tumor load in vivo and increased survival advantage. These studies provide evidence that $\mathrm{Vk}^{*} \mathrm{MYC} M \mathrm{MM}$ is a useful screening tool for anti-MM drugs and should aid in prioritization of novel drug testing in the clinic.

\section{Materials and Methods}

Cells, chemicals and antibodies. JJN3 cells were a gift from Andrew Spencer (The Alfred Hospital, Prahran, VIC, Australia). RPMI-8226, OPM-2 and U266 cells were a gift from Paul Neeson (Hematology and Immunology Translational Research Laboratory, Peter MacCallum Cancer Centre, East Melbourne, VIC, Australia). JJN3 cells were cultured in the medium containing 40\% IMDM, 40\% DMEM, 20\% FBS; OPM-2 and RPMI-8226 cells were cultured in 
RPMI 1640 containing 10\% FBS and L-glutamine; U266 cells were cultured in RPMI 1640 plus $15 \%$ FBS, sodium pyruvate, HEPES and L-glutamine. All cells were cultured with penicillin/streptomoycin. Vorinostat (suberoylanilide hydroxamic acid, SAHA) was obtained from Merck (Boston, MA, USA), panobinostat (LBH589) was obtained from Novartis Institutes for Biomedical Research (Cambridge, MA, USA), and romidepsin (Depsipeptide) and 5-AZA (Vidaza) were obtained from

a $\quad \mathbf{k}^{*} \mathrm{MYC}$ bone marrow
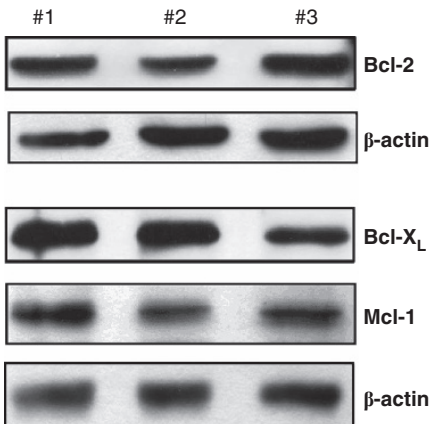

b

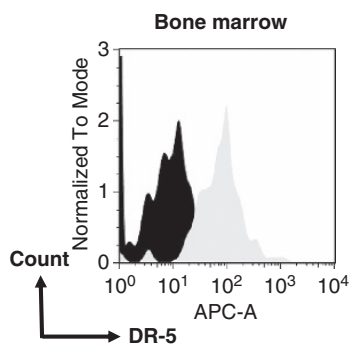

Figure 5 Expression of Bcl-2 prosurvival proteins and surface DR-5 on bone marrow cells from C57BL/6 mice bearing Vk*MYC MM. (a) Prosurvival Bcl-2 family protein expression in the bone marrow of mice bearing $\mathrm{Vk}^{*} \mathrm{MYC} M \mathrm{MM}$ by western blot $(n=3)$, and (b) assessment of surface DR-5 expression on B220 - /CD138+ plasma cells from bone marrow of a mouse bearing Vk*MYC MM by FACS. Black histogram $=$ isotype control; light gray histogram $=\mathrm{DR}-5$ expression
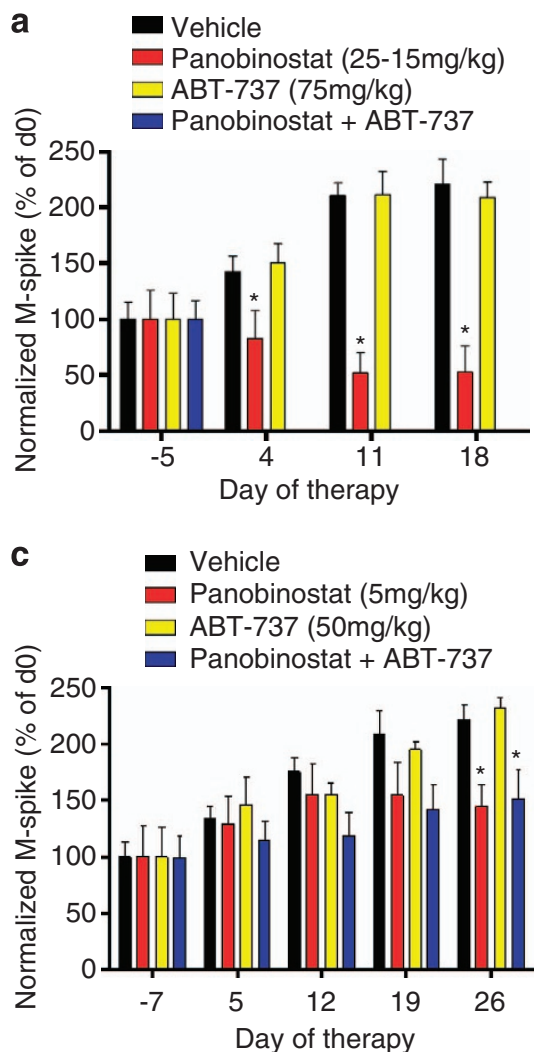

Celgene (Summit, NJ, USA). ABT-737 and ABT-737 enantiomer were obtained from Abbott (Abbot Park, IL, USA). rhTRAIL was obtained from Peprotech (Rocky Hill, NJ, USA). MD5-1 agonistic anti-mouse TRAILR Ab and control hamster mAb (UC8-1B9) were obtained from Hideo Yagita (Juntendo University School of Medicine, Tokyo, Japan). Western blotting antibodies included: anti-acetylated histone H3 (Millipore, Billerica, MA, USA); anti-hBcl-2 (SantaCruz Biotechnology, SantaCruz, CA, USA); anti-mBcl-2 (BD Pharmingen, North Ryde, NSW, Australia), anti-hBcl-xL (BD Pharmingen); anti-Mcl-1 (BD Pharmingen); anti-Bcl2-A1 (J Borst, The Netherlands Cancer Institute, Amsterdam, The Netherlands); anti-Bcl-w (16H12, Millipore); anti-hDR-4 and -hDR-5 (Imgenex, San Diego, CA, USA); anti-mDR-5 (BD Pharmingen); and anti-cFLIP $\mathrm{L}_{\mathrm{L}}$ NF6 (Alexis, Sapphire Biosciences, Waterloo, NSW, Australia).

In vitro apoptosis. Cells seeded $\left(2-5 \times 10^{5}\right.$ per well) into 24-well plates $(750 \mu l)$ were treated with vorinostat, panobinostat, romidesin, ABT-737, rhTRAIL or 5-AZA $(750 \mu l)$. For combination studies, MM cell lines were treated with panobinostat and ABT-737, rhTRAIL or 5-AZA in a checkerboard format: vehicle (750 $\mu \mathrm{l}$ medium); single agent for each drug $(375 \mu \mathrm{l}$ drug $+375 \mu \mathrm{l}$ medium); and combination drug treatments ( $375 \mu \mathrm{l}$ drug $\mathrm{A}+375 \mu \mathrm{l}$ drug B). For combination treatments consisting of panobinostat and 5-AZA, cells were pretreated with 5-AZA for $24 \mathrm{~h}$ before the addition of panobinostat. Apoptosis ( 24 and $48 \mathrm{~h}$ ) was assessed by FACS (Canto II; Becton Dickinson, Scoresby, VIC, Australia) using Annexin V-FITC and propidium iodide (PI) and results analyzed using the FlowJo software (version 7.6.5; Treestar, Ashland, OR, USA) and presented as the percentage of Annexin V-positive cells from at least three individual experiments.

Western blotting and quantitative real-time polymerase chain reaction. Cells seeded in six-well plates were treated with each agent for 8 , 16 or $24 \mathrm{~h}$, before freezing at $-80^{\circ} \mathrm{C}$. For protein expression by western blotting,
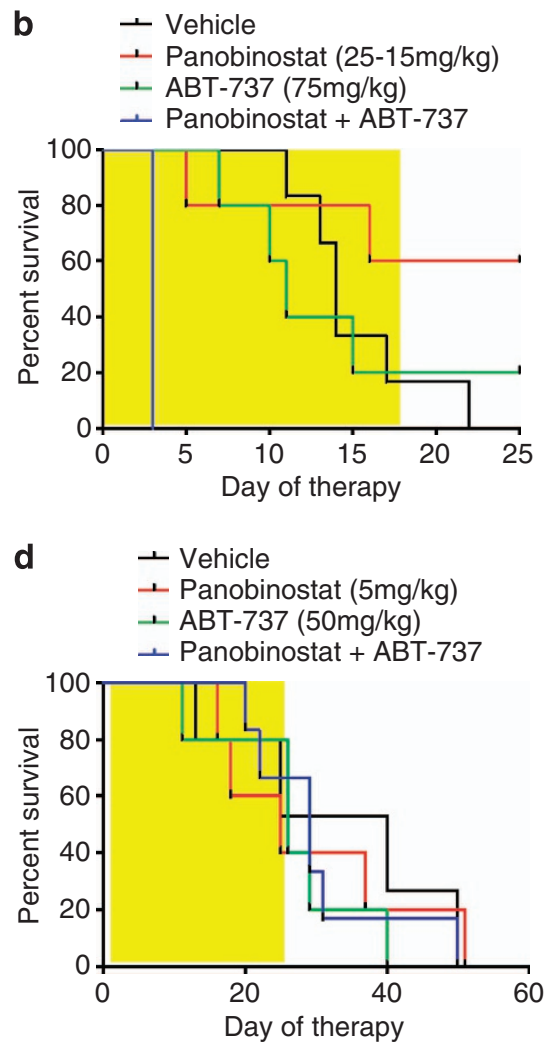

Figure 6 In vivo treatment of C57BL/6 mice bearing $\mathrm{Vk}^{*} \mathrm{MYC}$ MM reveals lack of therapeutic activity when panobinostat is combined with $\mathrm{ABT}-737$ above that of panobinostat treatment alone. (a) Single-agent therapy consisting of vehicle (D5W), high-dose panobinostat ( $25 \mathrm{mg} / \mathrm{kg}$ days $1-4,15 \mathrm{mg} / \mathrm{kg}$ remainder, 5 days per week), ABT-737 (75 mg/kg, 5 days per week) or the combination of both agents in mice bearing Vk*MYC MM. Normalized M-spike data over the 18 days of treatment. (b) Survival of mice treated with vehicle (D5W, $n=6$ ), panobinostat $(n=5)$, ABT-737 $(n=5)$ or the combination of both agents $(n=6)$. (c) Mice bearing Vk* MYC MM were then treated with lower doses of both agents as follows: vehicle ( $n=5)$; panobinostat $(5 \mathrm{mg} / \mathrm{kg}, 5$ days per week, $n=5)$; ABT-737 ( $50 \mathrm{mg} / \mathrm{kg}$, two times daily, $n=5)$; or the combination of both agents $(n=6)$, for 4 weeks. Results are depicted as normalized M-spike over the 26 days of treatment, and (d) survival of mice treated with the lower doses of both agents, alone and in combination. ${ }^{*} P<0.05$ versus vehicle 


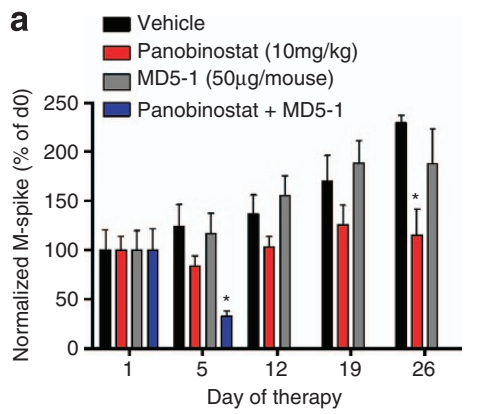

b
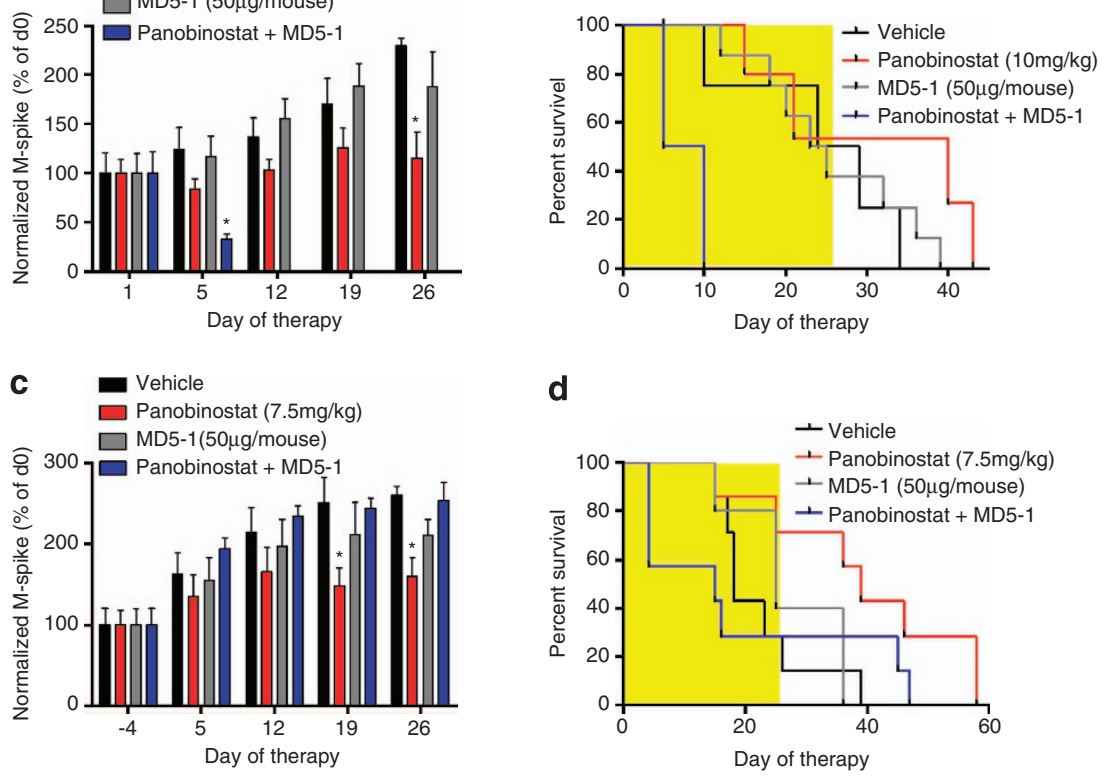

d
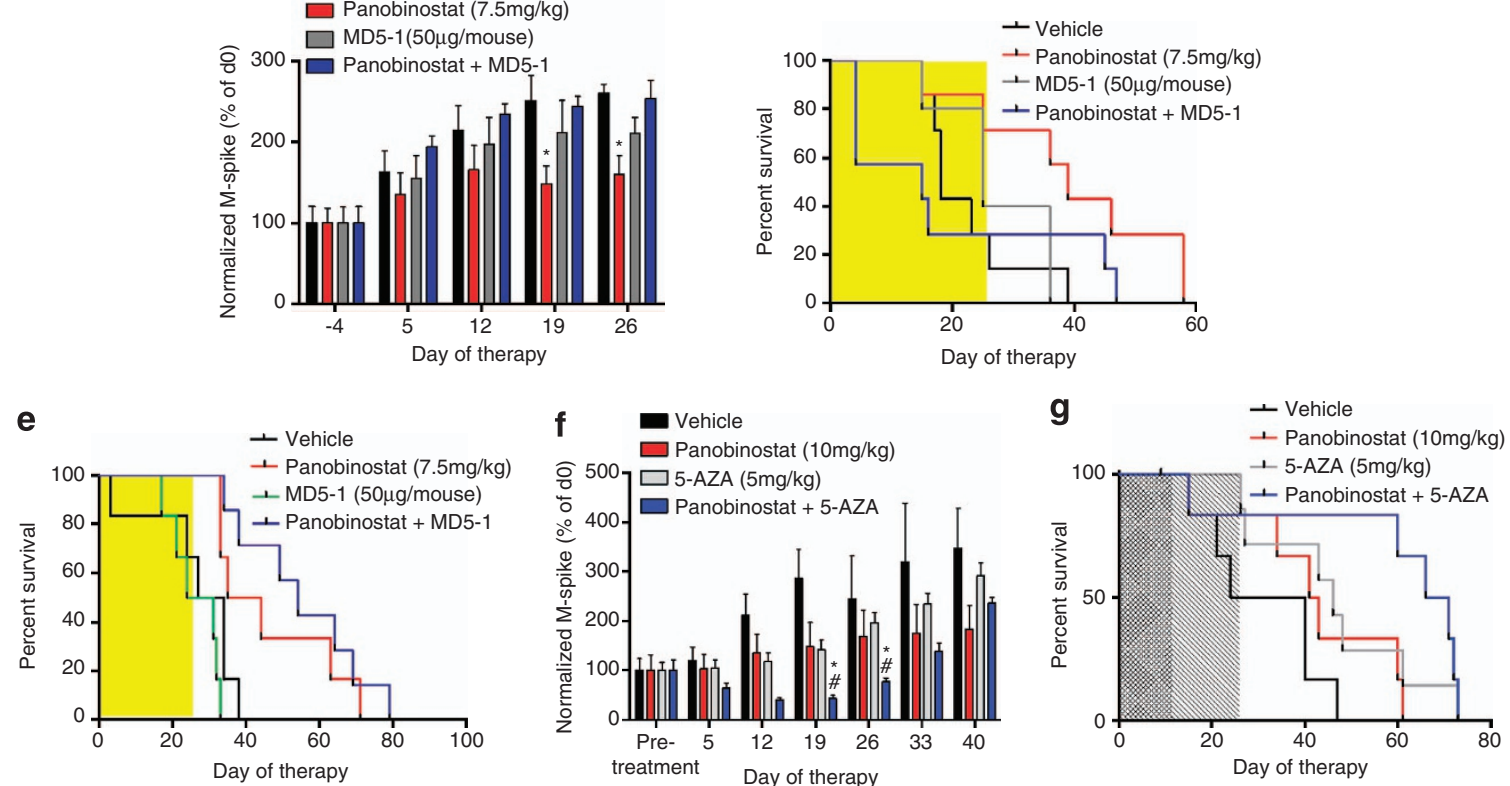

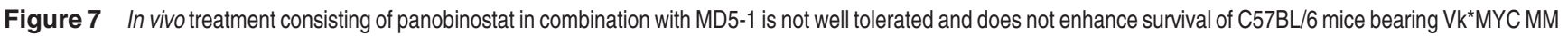
over single-agent panobinostat treatment alone, whereas its combination with 5-AZA provides significant benefit. (a) Normalized M-spike of mice bearing Vk* MYC MM treated as follows: vehicle (D5W \pm control antibody UC81B9, $n=8$ ); panobinostat (10 mg/kg, $n=6$ ); MD5-1 (50 $\mu$ g per mouse; days 1, 4, 8, 12; $n=8$ ); or the combination of both agents $(n=8)$. ${ }^{*} P<0.05$ versus vehicle. (b) Survival of mice treated as per 7A, (c) normalized M-spike of mice bearing Vk*MYC MM treated as follows: vehicle (D5W, $n=7$ ); panobinostat (7.5 mg/kg, $n=7$ ); MD5-1 (50 $\mu$ g per mouse; days 2, 5, 9, 12; $n=6$ ); or the combination of both agents $(n=7)$; (d) survival of mice treated as per (c); (e) absence of on-target MD5-1-mediated toxicity by treatment of C57BL/6.DR5 KO mice bearing Vk*MYC tumor with panobinostat and MD5-1 combination therapy leads to significant increases in survival. Mice were treated as follows: vehicle (D5W \pm control antibody UC81B9, $n=6$ ); panobinostat (7.5 mg/kg, $n=6$ ); MD5-1 (50 $\mu$ g per mouse, days 2, 5, 9, 12; $n=6$ ); or the combination of both agents $(n=7)$; (f) normalized M-spike of mice bearing Vk*MYC MM treated as follows: vehicle (D5W, $n=6)$, panobinostat $(10 \mathrm{mg} / \mathrm{kg}, n=6), 5$-AZA $(5 \mathrm{mg} / \mathrm{kg}, n=7)$ and the combination of both agents $(n=7)$. (g) Survival of mice treated as per (f). ${ }^{*} P<0.05$ versus vehicle and ${ }^{\#} P<0.05$ versus initial (pretreatment) SPEP

cell pellets were lysed (Triton X-100-based buffer) and protein concentration assessed. ${ }^{53}$ Samples $(20-40 \mu \mathrm{g})$ run into an SDS-PAGE gel (8-12\%), wet transferred onto Immobilin P membrane (Millipore) and blocked (1 h, 5\% skim milk). Primary antibodies were prepared in $5 \%$ skim milk in Tris-buffered saline with Tween (TBS-T) as follows: anti-acetylated histone $\mathrm{H} 3$, anti-Bcl-2, anti-Bcl- $\mathrm{X}_{\mathrm{L}}$, anti-Bcl-w, anti-Bcl-A1, anti-Mcl-1 and anti-cFLIP at 1/1000. $\beta$-Actin or $\alpha$-tubulin (1/2000) were used as loading controls. Primary antibodies were incubated overnight at $4{ }^{\circ} \mathrm{C}$. Secondary antibodies were prepared in $5 \%$ skim milk in TBS-T and incubated for $1 \mathrm{~h}$ at room temperature. Membranes were exposed to film after the addition of ECL (GE Healthcare, Melbourne, VIC, Australia). For assessment of c-FLIP mRNA expression, total RNA was obtained from cell pellets using Qiagen RNeasy mini kits (Qiagen, Doncaster, VIC, Australia) and reverse transcribed using M-MLV Reverse transcriptase (RNase $\mathrm{H}$ Minus, Point mutant) and random primers (Promega, Madison, WI, USA). Quantitative real-time polymerase chain reaction was undertaken using SYBR green fluorescent nucleic acid stain (Invitrogen, Mulgrave, VIC, Australia) and the following primers (Fwd: 5'-TGCCTCTCCCAGAAACTGAGA-3'; Rev: 5'-CCA
ATCATACATGTAGCCATTGAGT-3') in an ABI7900HT (Applied Biosystems, Mulgrave, VIC, Australia).

Oncomine database search. Microarray data sets were assessed using Oncomine Cancer Profiling Database (http: //www.oncomine.org/). The expression of prosurvival Bcl-2 genes in human JJN3, OPM-2, RPMI-8226 and U266 cells were obtained through Oncomine software 4.4.3 (Compendia Bioscience, Ann Arbor, MI, USA).

RNA sequencing. JJN3 and U266 cells were treated with panobinostat (4h), 5-AZA $(24+4 \mathrm{~h})$ or the combination of both agents $(24+4 \mathrm{~h})$ at doses deemed to be synergistic (Figure $4 b$ ), harvested and RNA extracted as described. Fifty base pair paired-end reads were generated on an Illumina Hiseq. Reads were quality checked by FastQC and trimmed if necessary for low base quality or adaptor, and then mapped to the human reference genome (GRCh37) using Tophat2 v.2.0.8b (PMID: 23618408) with maximum number of multiple hits set to 1 and using the option to map first to the reference 
transcriptome (Ensembl v.69). Counts per gene were obtained using HTSeq v.0.5.3p9 with mode intersection-nonempty (http: //www-huber.embl.de/users/ anders/HTSeq/doc/overview.html/). The limma-voom method was used to identify genes differentially expressed between each drug (or combination) and the vehicle control using a FDR threshold $<0.05$ (http: //www.statsci.org/ smyth/pubs/VoomTechReport.pdf/).

Gene set testing was performed using CAMERA ${ }^{40}$ and the MSigDB v.3.1 C2 curated gene sets collection. The genes in the RNA-seq data set were mapped to the Entrez IDs in the gene sets by first mapping the RNA-seq Ensembl gene IDs to Entrez IDs. Gene sets that contained fewer than 15 genes were excluded. After running CAMERA, two-sided $P$-values of $<0.05$ were applied to identify statistically significant signatures.

Analysis of DR-4 and DR-5 expression by FACS. Cell lines were suspended at $1 \times 10^{6} / 100 \mu \mathrm{l}$ in PBS and stained with anti-hDR-4, DR-5 (1/20) or isotype control for $30 \mathrm{~min}$ on ice. Cells were washed in PBS, stained with antiIgG-PE (1/200) for $30 \mathrm{~min}$ on ice, washed and analyzed on a Canto II (Becton Dickinson) flow cytometer.

Therapeutic assessment of antitumor agents. Recipient C57BL/6 mice (typically $n=10$ per intended treatment cohort) were injected intravenously with Vk MYC MM cells $\left(2-5 \times 10^{5}\right.$ per mouse) following conditioning with two fractions of 3 Gy irradiation. Mice were monitored for the onset of paraproteinemia by periodic serum protein electrophoresis (SPEP). Mice with established paraproteinemia ( $>5 \%$ of total protein) were grouped based on approximately equal mean paraprotein levels and randomly assigned to treatment groups. For determination of 'on-target' toxicity in response to MD5-1 treatment, Vk* MYC tumor was transplanted into C57BL/6.DR5 ${ }^{-1-}$ mice.

Mice bearing Vk*MYC tumor were treated for 4 weeks as follows: (a) vehicle (D5W, $200 \mu$ l daily), panobinostat ( $25 \mathrm{mg} / \mathrm{kg}$ days $1-4$, then $15 \mathrm{mg} / \mathrm{kg} 5$ days per week); (b) panobinostat (10, 7.5 or $5 \mathrm{mg} / \mathrm{kg}, 5$ days per week, intraperitoneally), ABT-737 (75 or $50 \mathrm{mg} / \mathrm{kg}$, intraperitoneally, two times daily), or the combination of both agents; (c) monoclonal control antibody (UC8-1B9, $50 \mu \mathrm{g}$ per mouse) in D5W, panobinostat (10 g or $7.5 \mathrm{mg} / \mathrm{kg}$ ), anti-mouse agonistic anti-TRAIL antibody MD5-1 (50 $\mu \mathrm{g}$ per mouse or $25 \mu \mathrm{g}$ per mouse) or the combination of both agents; and (d) panobinostat ( $10 \mathrm{mg} / \mathrm{kg}$ 5days per week, intraperitoneally), $5-\mathrm{AZA}(5 \mathrm{mg} / \mathrm{kg}$, two times daily, 12 days, intraperitoneally) or the combination of both agents. Therapeutic efficacy was assessed by serial SPEP obtained by retro-orbital sampling or tail grazing. Mice were culled by cervical dislocation at predetermined end points, including hind limb paralysis, cachexia and hunching.

Mice were maintained under specific pathogen-free conditions and used in accordance with the institutional guidelines of the Peter MacCallum Cancer Centre. Animal care was provided in accordance with the procedures outlined in the National Institutes of Health Guide for the Care and Use of Laboratory Animals.

Assessment of DR-5 expression on Vk*MYC tumor. Bone marrow suspensions from mice bearing transplanted $\mathrm{Vk}^{*} \mathrm{MYC}$ tumor were washed ( $2 \%$ FBS in PBS), red cell lysed and stained with anti-mB220-FITC (1/400), anti-mCD138-PE (1/500), anti-IgD-Pacblue (1/300), biotin-labeled anti-mDR5 $(1 / 500)$ or isotype control (Armenian hamster lgG, 1/500). Plates were set on ice for $30 \mathrm{~min}$, washed and stained with streptavidin-labeled secondary antibody conjugated to APC on ice for $30 \mathrm{~min}$. Following two washes, cells were resuspended in PBS containing fluorogold $(1 / 3000)$ and assessed for DR5 expression using an LSR II flow cytometer (Becton Dickinson).

Statistics. The sensitivity of MM cell lines to tested agents were compared using GraphPad software (Prism, GraphPad Software Inc., La Jolla, CA, USA). Combination drug experiments were assessed for synergy, additivity or antagonism using Calcusyn (Biosoft, Cambridge, UK), which uses the medianeffect equation of Chou and Talalay. ${ }^{54}$ Statistical analyses of in vivo therapy assays were performed using one-way analysis of variances (ANOVA) with post hoc tests. Median survival between treatment groups were compared using Kaplan-Meier curves and the GraphPad software. Significance was assumed with $P<0.05$.

\section{Conflict of Interest}

GMM, ML, MD, JS, JE, KB, EV and DF declare no conflict of interest. The laboratory of RWJ receives research funding from Novartis for studies involving panobinostat. PA is an employee of Novartis. PLB and MC hold intellectual property in Vk*MYC mice.

Acknowledgements. We thank Dr Hideo Yagita for the provision of MD5-1. GMM was supported by funding from the National Health and Medical Research Council (NHMRC) of Australia. JS was supported by funding from the Leukaemia Foundation of Australia and the Co-operative Research Centre for Biomedical Imaging Development. RWJ is a Principal Research Fellow of the NHMRC of Australia and supported by NHMRC Program and Project Grants, the Susan G Komen Breast Cancer Foundation, Cancer Council Victoria, The Leukaemia Foundation of Australia, Victorian Breast Cancer Research Consortium and the Victorian Cancer Agency. ML is supported by the Leukaemia Foundation of Australia. This work was supported by National Institutes of Health Grant AG20686, National Cancer Institute Grant CA136671 (PLB) and by the Multiple Myeloma Research Foundation (MC)

1. Kyle RA, Buadi F, Rajkumar SV. Management of monoclonal gammopathy of undetermined significance (MGUS) and smoldering multiple myeloma (SMM). Oncology (Williston Park) 2011; 25: 578-586.

2. Kyle RA, Rajkumar SV. Multiple myeloma. N Engl J Med 2004; 351: 1860-1873.

3. Chesi M, Robbiani DF, Sebag M, Chng WJ, Affer M, Tiedemann R et al. AID-dependent activation of a MYC transgene induces multiple myeloma in a conditional mouse model of post-germinal center malignancies. Cancer Cell 2008; 13: 167-180.

4. Kyle RA, Rajkumar SV. Criteria for diagnosis, staging, risk stratification and response assessment of multiple myeloma. Leukemia 2009; 23: 3-9.

5. Azab AK, Runnels JM, Pitsillides C, Moreau AS, Azab F, Leleu X et al. CXCR4 inhibitor AMD3100 disrupts the interaction of multiple myeloma cells with the bone marrow microenvironment and enhances their sensitivity to therapy. Blood 2009; 113: 4341-4351.

6. Khong T, Sharkey J, Spencer A. The effect of azacitidine on interleukin-6 signaling and nuclear factor-kappaB activation and its in vitro and in vivo activity against multiple myeloma. Haematologica 2008; 93: 860-869.

7. Utecht KN, Kolesar J. Bortezomib: a novel chemotherapeutic agent for hematologic malignancies. Am J Health Syst Pharm 2008; 65: 1221-1231.

8. Atadja PW. HDAC inhibitors and cancer therapy. Prog Drug Res 2011; 67: 175-195

9. Bolden JE, Peart MJ, Johnstone RW. Anticancer activities of histone deacetylase inhibitors. Nat Rev Drug Discov 2006; 5: 769-784.

10. Khan $\mathrm{O}$, La Thangue NB. HDAC inhibitors in cancer biology: emerging mechanisms and clinical applications. Immunol Cell Biol 2012; 90: 85-94.

11. Fantin V, Richon VM. Mechansims of resistance to histone deacetylase inhibitors and their therapeutic implications. Clin Cancer Res 2007; 13: 7237-7242.

12. Hacker S, Dittrich A, Mohr A, Schweitzer T, Rutkowski S, Krauss J et al. Histone deacetylase inhibitors cooperate with IFN-gamma to restore caspase-8 expression and overcome TRAIL resistance in cancers with silencing of caspase-8. Oncogene 2009; 28 : 3097-3110

13. Rasheed W, Bishton M, Johnstone R, Prince M. Histone deacetylase inhibitors in lymphoma and solid malignancies. Expert Rev Anticancer Ther 2008; 8: 413-432.

14. Vanoosten RL, Moore JM, Ludwig AT, Griffith TS. Depsipeptide (FR901228) enhances the cytotoxic activity of TRAIL by redistributing TRAIL receptor to membrane lipid rafts. Mol Ther 2005; 11: 542-552.

15. Atadja P. Development of the pan-DAC inhibitor panobinostat (LBH589): successes and challenges. Cancer Lett 2009; 280: 233-241.

16. Maiso P, Carvajal-Vergara X, Ocio EM, Lopez-Perez R, Mateo G, Gutierrez N et al. The histone deacetylase inhibitor LBH589 is a potent antimyeloma agent that overcomes drug resistance. Cancer Res 2006; 66: 5781-5789.

17. Martin BP, Frew AJ, Bots M, Fox S, Long F, Takeda $\mathrm{K}$ et al. Antitumor activities and on-target toxicities mediated by a TRAIL receptor agonist following cotreatment with panobinostat. Int J Cancer 2011; 128: 2735-2747.

18. Buchwald M, Kramer OH, Heinzel T. HDACi-targets beyond chromatin. Cancer Lett 2009; 280: $160-167$.

19. Chipuk JE, Green DR. How do BCL-2 proteins induce mitochondrial outer membrane permeabilization? Trends Cell Biol 2008; 18: 157-164.

20. Chipuk JE, Moldoveanu T, Llambi F, Parsons MJ, Green DR. The BCL-2 family reunion. Molecular Cell 2010; 37: 299-310.

21. Konopleva M, Contractor R, Tsao T, Samudio I, Ruvolo PP, Kitada S et al. Mechanisms of apoptosis sensitivity and resistance to the $\mathrm{BH} 3$ mimetic ABT-737 in acute myeloid leukemia. Cancer Cell 2006; 10: 375-388.

22. Lessene G, Czabotar PE, Colman PM. BCL-2 family antagonists for cancer therapy. Nat Rev Drug Discov 2008; 7: 989-1000.

23. Letai A. Pharmacological manipulation of Bcl-2 family members to control cell death. $J$ Clin Invest 2005; 115: 2648-2655.

24. Letai A. BCL-2: found bound and drugged! Trends Mol Med 2005; 11: 442-444. 
25. Oltersdorf T, Elmore SW, Shoemaker AR, Armstrong RC, Augeri DJ, Belli BA et al. An inhibitor of Bcl-2 family proteins induces regression of solid tumours. Nature 2005; 435 : 677-681.

26. Trudel S, Stewart AK, Li Z, Shu Y, Liang SB, Trieu Y et al. The Bcl-2 family protein inhibitor, ABT-737, has substantial antimyeloma activity and shows synergistic effect with dexamethasone and melphalan. Clin Cancer Res 2007; 13(Part 1): 621-629.

27. Johnstone RW, Frew AJ, Smyth MJ. The TRAIL apoptotic pathway in cancer onset, progression and therapy. Nat Rev Cancer 2008; 8: 782-798.

28. Wang $\mathrm{S}$. The promise of cancer therapeutics targeting the TNF-related apoptosis-inducing ligand and TRAIL receptor pathway. Oncogene 2008; 27: 6207-6215.

29. Frew AJ, Johnstone RW, Bolden JE. Enhancing the apoptotic and therapeutic effects of HDAC inhibitors. Cancer Lett 2009; 280: 125-133.

30. Frew AJ, Lindemann RK, Martin BP, Clarke CJ, Sharkey J, Anthony DA et al. Combination therapy of established cancer using a histone deacetylase inhibitor and a TRAIL receptor agonist. Proc Natl Acad Sci USA 2008; 105: 11317-11322.

31. Whitecross KF, Alsop AE, Cluse LA, Wiegmans A, Banks K-M, Coomans $C$ et al. Defining the target specificity of ABT-737 and synergistic antitumor activities in combination with histone deacetylase inhibitors. Blood 2009; 113: 1982-1991.

32. Wiegmans AP, Alsop A, Bots M, Cluse LA, Williams SP, Banks K-M et al. Deciphering the molecular events necessary for synergistic tumor cell apoptosis mediated by the histone deacetylase inhibitor vorinostat and the BH3 mimetic ABT-737. Cancer Res 2011; 71: 3603-3615.

33. Smith EM, Boyd K, Davies FE. The potential role of epigenetic therapy in multiple myeloma. Br J Haematol 2010; 148: 702-713.

34. Nojima M, Maruyama R, Yasui H, Suzuki H, Maruyama Y, Tarasawa I et al. Genomic screening for genes silenced by DNA methylation revealed an association between RASD1 inactivation and dexamethasone resistance in multiple myeloma. Clin Cancer Res 2009; 15: 4356-4364.

35. Chesi M, Matthews GM, Garbitt VM, Palmer SE, Shortt J, Lefebure M et al. Drug response in a genetically engineered mouse model of multiple myeloma is predictive of clinical efficacy. Blood 2012; 120: 376-385.

36. Chng WJ, Huang GF, Chung TH, Ng SB, Gonzalez-Paz N, Troska-Price T et al. Clinical and biological implications of MYC activation: a common difference between MGUS and newly diagnosed multiple myeloma. Leukemia 2011; 25: 1026-1035.

37. Ellis L, Bots M, Lindemann RK, Bolden JE, Newbold A, Cluse LA et al. The histone deacetylase inhibitors LAQ824 and LBH589 do not require death receptor signaling or a functional apoptosome to mediate tumor cell death or therapeutic efficacy. Blood 2009; 114: 380-393.

38. Lindemann RK, Newbold A, Whitecross KF, Cluse LA, Frew AJ, Ellis L et al. Analysis of the apoptotic and therapeutic activities of histone deacetylase inhibitors by using a mouse model of B cell lymphoma. Proc Natl Acad Sci USA 2007; 104: 8071-8076.

39. Ruefli AA, Ausserlechner MJ, Bernhard D, Sutton VR, Tainton KM, Kofler R et al. The histone deacetylase inhibitor and chemotherapeutic agent suberoylanilide hydroxamic acid (SAHA) induces a cell-death pathway characterized by cleavage of Bid and production of reactive oxygen species. Proc Natl Acad Sci USA 2001; 98: 10833-10838.

40. Wu D, Smyth GK. Camera: a competitive gene set test accounting for inter-gene correlation. Nucleic Acids Res 2012; 40: e133.
41. Deleu S, Lemaire M, Arts J, Menu E, Van Valckenborgh E, Vande Broek I et al. Bortezomib alone or in combination with the histone deacetylase inhibitor JNJ-26481585: effect on myeloma bone disease in the 5T2MM murine model of myeloma. Cancer Res 2009; 69: 5307-5311.

42. Feng R, Oton A, Mapara MY, Anderson G, Belani C, Lentzsch S. The histone deacetylase inhibitor, PXD101, potentiates bortezomib-induced anti-multiple myeloma effect by induction of oxidative stress and DNA damage. Br J Haematol 2007; 139: 385-397.

43. Mitsiades N, Mitsiades CS, Richardson PG, McMullan C, Poulaki V, Fanourakis G et al. Molecular sequelae of histone deacetylase inhibition in human malignant $B$ cells. Blood 2003; 101: 4055-4062.

44. Zhang L, Fang B. Mechanisms of resistance to TRAIL-induced apoptosis in cancer. Cancer Gene Ther 2004; 12: 228-237.

45. Guo F, Sigua C, Tao J, Bali P, George P, Li Y et al. Cotreatment with histone deacetylase inhibitor LAQ824 enhances Apo-2L/tumor necrosis factor-related apoptosis inducing ligand-induced death inducing signaling complex activity and apoptosis of human acute leukemia cells. Cancer Res 2004; 64: 2580-2589.

46. Kauh J, Fan S, Xia M, Yue P, Yang L, Khuri FR et al. c-FLIP degradation mediates sensitization of pancreatic cancer cells to TRAIL-induced apoptosis by the histone deacetylase inhibitor LBH589. PLoS One 2010; 5: e10376.

47. Perez LE, Parquet N, Shain K, Nimmanapalli R, Alsina M, Anasetti C et al. Bone marrow stroma confers resistance to Apo2 ligand/TRAIL in multiple myeloma in part by regulating C-FLIP. J Immunol 2008; 180: 1545-1555.

48. Gomez-Benito M, Martinez-Lorenzo MJ, Anel A, Marzo I, Naval J. Membrane expression of DR4, DR5 and caspase-8 levels, but not Mcl-1, determine sensitivity of human myeloma cells to Apo2L/TRAIL. Exp Cell Res 2007; 313: 2378-2388.

49. Brennan SK, Matsui W. Cancer stem cells: controversies in multiple myeloma. J Mol Med (Berl) 2009; 87: 1079-1085.

50. Labrinidis A, Diamond P, Martin S, Hay S, Liapis V, Zinonos I et al. Apo2L/TRAIL inhibits tumor growth and bone destruction in a murine model of multiple myeloma. Clin Cancer Res 2009; 15: 1998-2009.

51. Vogler M, Butterworth M, Majid A, Walewska RJ, Sun XM, Dyer MJ et al. Concurrent up-regulation of BCL-XL and BCL2A1 induces approximately 1000 -fold resistance to $A B T$ 737 in chronic lymphocytic leukemia. Blood 2009; 113: 4403-4413.

52. Vogler M, Dinsdale D, Dyer MJS, Cohen GM. Bcl-2 inhibitors: small molecules with a big impact on cancer therapy. Cell Death Differ 2008; 16: 360-367.

53. Bradford MM. A rapid and sensitive method for the quantitation of microgram quantities of protein utilizing the principle of protein-dye binding. Anal Biochem 1976; 72: 248-254.

54. Chou TC. Drug combination studies and their synergy quantification using the Chou-Talalay method. Cancer Res 2010; 70: 440-446.

cc) (i) $(\theta)$ Cell Death and Disease is an open-access journal cc) licensed under a Creative Commons Attribution-NonCommercialNoDerivs 3.0 Unported License. To view a copy of this license, visit http://creativecommons.org/licenses/by-nc-nd/3.0/

\section{Supplementary Information accompanies this paper on Cell Death and Disease website (http://www.nature.com/cddis)}

